\title{
Therapeutic endoscopic ultrasound: European Society of Gastrointestinal Endoscopy (ESGE) Guideline
}

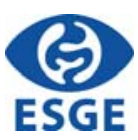

Authors

Schalk W. van der Merwe ${ }^{1}$, Roy L. J. van Wanrooij ${ }^{\circledR}{ }^{\oplus}$, Michiel Bronswijk1,3 $\odot$, Simon Everett ${ }^{4}$, Sundeep Lakhtakia ${ }^{5}$, Mihai Rimbas $^{6}{ }^{\oplus}$, Tomas Hucl${ }^{7}$, Rastislav Kunda ${ }^{8}{ }^{\oplus}$, Abdenor Badaoui ${ }^{9}$, Ryan Law ${ }^{10}$, Paolo G. Arcidiacono ${ }^{11}$, Alberto Larghi $^{12}$, Marc Giovannini ${ }^{13}$, Mouen A. Khashab ${ }^{14}$, Kenneth F. Binmoeller ${ }^{15}$, Marc Barthet ${ }^{16} \oplus^{\oplus}$, Manuel Perez-Miranda ${ }^{17}$ (ㄹ, Jeanin E. van Hooft ${ }^{18}$ ()

Institutions

1 Department of Gastroenterology and Hepatology, University Hospitals Leuven, Leuven, Belgium

2 Department of Gastroenterology and Hepatology, Amsterdam UMC, Vrije Universiteit Amsterdam, AGEM Institute, Amsterdam, The Netherlands

3 Department of Gastroenterology and Hepatology, Imelda General Hospital, Bonheiden, Belgium

4 Department of Gastroenterology and Hepatology, Leeds Teaching Hospital NHS Trust, Leeds, UK

5 Department of Medical Gastroenterology, Asian Institute of Gastroenterology Hospitals, Gachibowli, Hyderabad, India

6 Gastroenterology Department, Colentina Clinical Hospital, Bucharest, Romania

7 Department of Gastroenterology and Hepatology, Institute for Clinical and Experimental Medicine, Prague, Czech Republic

8 Department of Surgery, Department of Gastroenterology and Hepatology, and Department of Advanced Interventional Endoscopy, Universitair Ziekenhuis Brussel, Vrije Universiteit Brussel, Brussels, Belgium

9 Department of Gastroenterology and Hepatology, Université catholique de Louvain, CHU UCL Namur, Yvoir, Belgium

10 Department of Gastroenterology and Hepatology, Mayo Clinic, Rochester, Minnesota, USA

11 Pancreatobiliary Endoscopy and Endosonography Division, IRCCS San Raffaele Scientific Institute, Milan, Italy

12 Digestive Endoscopy Unit, Fondazione Policlinico Universitario A. Gemelli IRCCS, Università Cattolica del Sacro Cuore, and Center for Endoscopic Research Therapeutics and Training (CERTT), Catholic University, Rome, Italy

13 Paoli-Calmettes Institute, Department of Gastrointestinal Disease, Marseille, France
14 Division of Gastroenterology and Hepatology, Johns Hopkins Hospital, Baltimore, Maryland, USA

15 Interventional Endoscopy Services, California Pacific Medical Center, San Francisco, California, USA

16 Department of Gastroenterology, Aix-Marseille Université, APHM, Hôpital Nord, Marseille, France

17 Gastroenterology Department, Hospital Universitario Rio Hortega, Valladolid, Spain

18 Department of Gastroenterology and Hepatology, Leiden University Medical Center, Leiden, The Netherlands

published online 22.12.2021

Bibliography

Endoscopy 2022; 54: 185-205

DOI 10.1055/a-1717-1391

ISSN 0013-726X

(C) 2021. European Society of Gastrointestinal Endoscopy All rights reserved.

This article is published by Thieme.

Georg Thieme Verlag KG, Rüdigerstraße 14,

70469 Stuttgart, Germany

丹 Supplementary material

Supplementary material is available under

https://doi.org/10.1055/a-1717-1391

Corresponding author

Schalk W. van der Merwe, MD PhD, Department of

Gastroenterology and Hepatology, University Hospital

Leuven, Belgium

Schalk.vandermerwe@uzleuven.be

\section{MAIN RECOMMENDATIONS}

1 ESGE recommends the use of endoscopic ultrasoundguided biliary drainage (EUS-BD) over percutaneous transhepatic biliary drainage (PTBD) after failed endoscopic 
retrograde cholangiopancreatography (ERCP) in malignant distal biliary obstruction when local expertise is available. Strong recommendation, moderate quality evidence.

2 ESGE suggests EUS-BD with hepaticogastrostomy only for malignant inoperable hilar biliary obstruction with a dilated left hepatic duct when inadequately drained by ERCP and/ or PTBD in high volume expert centers.

Weak recommendation, moderate quality evidence.

3 ESGE recommends that EUS-guided pancreatic duct (PD) drainage should only be considered in symptomatic patients with an obstructed PD when retrograde endoscopic intervention fails or is not possible.

Strong recommendation, low quality evidence.

4 ESGE recommends rendezvous EUS techniques over transmural PD drainage in patients with favorable anatomy owing to its lower rate of adverse events.

Strong recommendation, low quality evidence.

5 ESGE recommends that, in patients at high surgical risk, EUS-guided gallbladder drainage (GBD) should be favored over percutaneous gallbladder drainage where both techniques are available, owing to the lower rates of adverse events and need for re-interventions in EUS-GBD.

Strong recommendation, high quality of evidence.

6 ESGE recommends EUS-guided gastroenterostomy (EUS-GE), in an expert setting, for malignant gastric outlet obstruction, as an alternative to enteral stenting or surgery. Strong recommendation, low quality evidence.

7 ESGE recommends that EUS-GE may be considered in the management of afferent loop syndrome, especially in the setting of malignancy or in poor surgical candidates.

Strong recommendation, low quality evidence.

8 ESGE suggests that endoscopic ultrasound-directed transgastric ERCP (EDGE) can be offered, in expert centers, to patients with a Roux-en-Y gastric bypass following multidisciplinary decision-making, with the aim of overcoming the invasiveness of laparoscopy-assisted ERCP and the limitations of enteroscopy-assisted ERCP.

Weak recommendation, low quality evidence.
SOURCE AND SCOPE

This Guideline is an official statement of the European Society of Gastrointestinal Endoscopy (ESGE). It provides guidance on the performance of therapeutic endoscopic ultrasound. The Grading of Recommendations Assessment, Development and Evaluation (GRADE) system was adopted to define the strength of recommendations and the quality of evidence.

\section{Introduction}

Since its development, endoscopic ultrasound (EUS) has become an established diagnostic modality that allows visualization of previously inaccessible anatomical regions with the capability of obtaining tissue for diagnosis. Optimization of imaging quality and Doppler, coupled with the development of linear array echoendoscopes with large therapeutic channels, has allowed access to fluid collections, the pancreatic and biliary ducts, as well as luminal structures adjacent to the gastrointestinal (GI) tract. With the use of fine-needle aspiration (FNA) needles and guidewires under real-time endosonographic and fluoroscopic control, these structures can be accessed to allow therapeutic procedures.

Given the tremendous advances made in this field, the European Society of Gastrointestinal Endoscopy (ESGE) has elected to publish guidelines on the use of therapeutic EUS. A previous ESGE guideline addressed EUS-guided management of fluid collections in acute necrotizing pancreatitis [1]. The current guideline will focus on EUS-guided drainage of the pancreaticobiliary system and its use in Gl-tract anastomosis. This guideline will be published in conjunction with an ESGE technical review where practical aspects related to these procedures, as well as salvage procedures should adverse events (AEs) occur, will be comprehensively described.

\section{Methods}

ESGE commissioned this guideline and appointed a coordinating team (S.v.d.M., J.H., R.W., M.Br.). A team of experts across different domains in therapeutic EUS was convened in May 2020. Two task force leaders were appointed (M.Ba. and M.P.M.) and their team members were instructed to scrutinize the literature for relevant articles pertaining to their fields of expertise. Topic-specific clinical key questions were generated by each task force. Searches were performed on Medline (via Pubmed) and the Cochrane library up to June 2021. The level of evidence for each question was scored according to the Grading of Recommendations Assessment, Development and Evaluation (GRADE) system into high, moderate, low, or very low [2]. Recommendations were drafted and the strength of each was determined as strong or weak. In addition, various web meetings were held to discuss and resolve issues, and formulate recommendations.

In July 2021, a final draft was sent to all group members for review. After all authors approved the final version, the manuscript was submitted to Endoscopy for publication. ESGE acknowledges that the field of therapeutic EUS is rapidly changing and that continued efforts will be required in the future to 


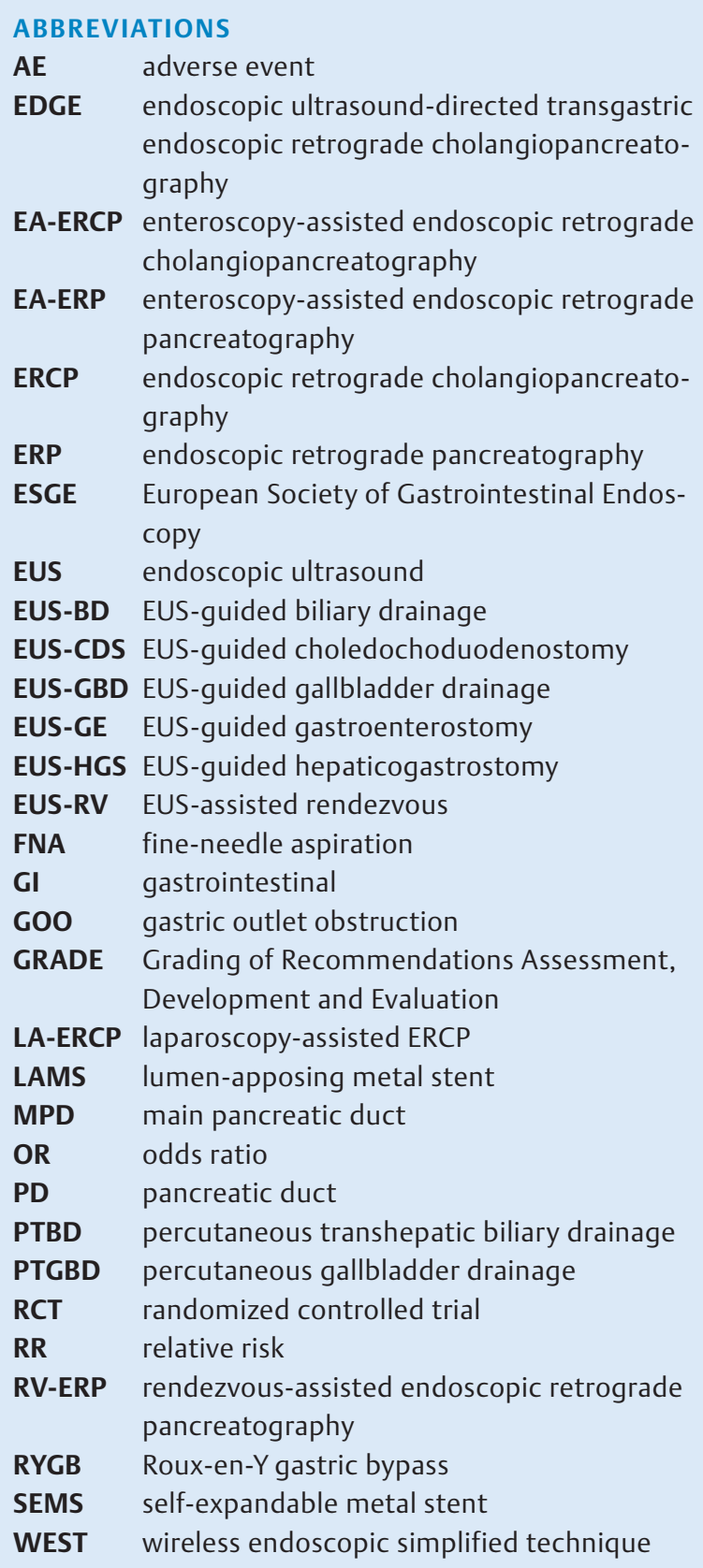

update and maintain these guidelines as additional high quality published data are generated.

\section{Definitions}

In general, terminology in therapeutic EUS procedures is not standardized. In this overview, ESGE aims to provide a framework by which these procedures should best be defined.

\subsection{EUS-assisted vs. EUS-guided techniques}

An "EUS-assisted" technique refers to the use of EUS to facilitate another procedure. The prime example of an EUS-assisted technique is rendezvous, where EUS facilitates the introduction of a guidewire across the papilla, stricture, or anastomosis to within reach of a duodenoscope. The linear echoendoscope is then exchanged for a duodenoscope to complete the procedure. An EUS-assisted technique is therefore an "indirect technique" performed using two endoscopes.

"EUS-guided" interventions refer to procedures performed exclusively under EUS guidance and are considered "direct techniques". These procedures can be performed in multiple steps following access to the target organ with an FNA needle and guidewire that allows insertion of various tools and placement of a stent. Alternatively, an all-in-one electrocauteryenhanced platform may be used, with placement of a lumenapposing metal stent (LAMS), using "freehand" introduction of the device into the target structure without prior placement of a guidewire. The latter technique may obviate the need for multiple accessory exchanges. Some EUS-guided interventions may further be assisted by the use of additional accessories, such as nasobiliary or other catheters, or balloons, to facilitate these procedures.

While indirect techniques enable retrograde drainage by endoscopic retrograde cholangiopancreatography (ERCP), direct techniques may allow antegrade or transmural drainage. Antegrade procedures reinstate the normal flow direction by bridging a stenosis and/or the papilla, whereas transmural drainage redirects the flow away from the normal drainage route by creating a new anastomosis.

\section{Biliary and pancreatic duct drainage}

ERCP remains the standard of care for the endoscopic management of many pancreaticobiliary disorders; however, conventional ERCP may not be feasible in patients with surgically altered $\mathrm{Gl}$ anatomy, luminal obstruction preventing access to the major and minor papilla, or failed cannulation of the pancreatic and bile ducts. The therapeutic role of EUS has evolved to become a complementary technique to ERCP to provide adequate drainage in such patients. EUS allows visualization of the intra- and extrahepatic biliary tree and the pancreatic duct $(P D)$, and serves as a platform for various successful drainage strategies, as described above and in the sections that follow.

Procedural consent for EUS-guided pancreaticobiliary drainage procedures should emphasize the technical aspects of the procedure, as well as the potential AEs. The complexity and risks associated with these procedures should not be understated. In selected clinical scenarios, procedural consent for EUSguided drainage should be obtained prior to conventional ERCP, in anticipation of failed cannulation, to achieve adequate drainage within the same session.

Expert consensus and current guidelines recommend that EUS-guided pancreaticobiliary drainage procedures should be performed by dedicated pancreaticobiliary endoscopists in rooms equipped with both EUS and fluoroscopy [3-6], with sur- 
gical and interventional radiology support available in the event of failure or severe AEs.

\subsection{Key question 1: What are the main approaches that employ EUS to achieve biliary drainage?}

EUS-guided biliary drainage (EUS-BD) can be performed by one of three methods. With EUS-assisted rendezvous (EUS-RV), an EUS-FNA needle is advanced under endosonographic guidance into an intra- or extrahepatic bile duct, allowing guidewire passage through the papilla for subsequent retrieval using a duodenoscope, thereby allowing conventional biliary ERCP to be performed.

Alternatively, EUS-guided direct transluminal stenting using either a transgastric (EUS-guided hepaticogastrostomy [HGS]) or transduodenal (EUS-guided choledochoduodenostomy [CDS]) approach may be performed without accessing the papilla. With these two techniques, the entire procedure is performed using the echoendoscope, with either the common bile duct or intrahepatic bile ducts being connected to the duodenum or stomach, respectively, using a stent.

A further method that may be considered is antegrade transpapillary (or transanastomotic) stent placement. With this technique, a guidewire is advanced and manipulated across the stenosis, either via the transpapillary or transanastomotic route, prior to stent placement.

\subsection{Key question 2: What are the technical and clinical success rates of each approach?}

\subsubsection{What are the definitions of "technical success" and "clinical success"?}

In EUS-RV techniques, guidewire passage from the biliary system into the small bowel that allows conventional ERCP to be performed defines technical success, while clinical success is attributable to the outcomes of the subsequently performed ERCP. For all other EUS-BD procedures in patients with malignant biliary obstruction, correct transmural or transpapillary stent placement resulting in flow of bile into the Gl tract identifies technical success, while a post-procedural (i.e. within 2-4 weeks) reduction in bilirubin of $50 \%-75 \%$ from preprocedural values indicates clinical success.

For patients with benign disease, successful biliary access defines technical success, while resolution of the clinical indication for which EUS-guided biliary intervention was performed indicates clinical success.

\subsubsection{Do different EUS-BD approaches have different success rates in malignant disease?}

Available data from retrospective studies, randomized controlled trials (RCTs), and meta-analyses have reported comparable technical and clinical success rates for EUS-CDS and EUSHGS (Tables $1 \mathbf{s}$ and $\mathbf{2 s}$, see online-only Supplementary material) [7-37]. Pooled data from studies directly comparing these two techniques in 303 and 329 patients respectively, estimated technical and clinical success rates of $94 \%$ and $88 \%$ for EUSCDS, and $96 \%$ and $87 \%$ for EUS-HGS (Table 3 s) [10, 18, 19, 30,
38-46]. No comparative studies of the remaining approaches are available.

Most studies describing EUS-RV procedures in malignant biliary obstruction also contain data on patients with benign disease (Table 4s) [28,47-52], thereby limiting the generalizability of the outcomes data. Overall, technical success rates of EUS-RV procedures ranged between $72 \%$ and $98 \%$ (Table 4 s), with a mean of $84 \%$, similar to that which is reported in metaanalyses [53]. In the only available studies describing the outcomes of EUS-guided antegrade stent placement in patients with surgically altered anatomy, technical and clinical success rates varied from $86 \%$ to $95 \%$ and $71 \%$ to $95 \%$, respectively (Table 5s) [33,54]. Finally, EUS-guided gallbladder drainage (EUS-GBD) to decompress malignant distal biliary obstruction has shown excellent results, with $100 \%$ technical success, and clinical success ranging between $91.7 \%$ and $92.7 \%$, albeit in a limited number of patients. It is currently regarded as a salvage procedure should other techniques fail (Table $6 \mathbf{s}$ ) $[55,56]$.

\subsubsection{Do different EUS-BD approaches have different success rates in benign disease?}

EUS-BD outcomes reported in patients with benign disease include those in whom ERCP failed [57-60] or where ERCP could not be performed owing to surgically altered anatomy $[58,59$, $61,62]$. Both the indications for EUS-BD and the approach used vary widely among the published studies, making comparisons difficult to interpret. EUS-RV was the primary technique in three studies $[57,60,63]$, while in the remaining studies transmural "tubular" self-expandable metal stent (SEMS) placement via various drainage pathways (i.e. HGS, CDS, or hepaticojejunostomy) was performed $[58,59,61,62]$. Technical success ranged between $77 \%$ and $83 \%$ in those studies involving EUSRV $[57,60,63]$. When transmural drainage with a SEMS was used, technical and clinical success approached $100 \%[24,58$, $59,61]$, with only one study reporting technical and clinical failures in $8 \%$ of patients [62].

\subsection{Key question 3: What are the indications for EUS-BD?}

EUS-BD has primarily been used as rescue therapy after failed ERCP. EUS-BD enables direct access to the bile ducts from either the stomach or the duodenum without the need to reach the papilla. As such, EUS-BD is feasible in patients with an endoscopically inaccessible papilla, as well as in patients with surgically altered anatomy.

When cannulation of the bile duct fails during ERCP, multiple strategies can be adopted using EUS-BD. The optimal drainage strategy depends on the underlying disease (benign/malignant) and the location of the obstruction (distal/hilar). In benign disease, such as common bile duct stones, EUS-BD allows placement of a guidewire across the papilla to facilitate ERCP via EUS-RV [64].

In malignant biliary obstruction, EUS-RV techniques may also enable placement of a transpapillary stent [65]. Alternatively, other options include the creation of a new anastomosis (EUS-HGS, EUS-CDS) upstream from the obstruction, potentially avoiding post-procedural pancreatitis. In malignant distal 
biliary obstruction, all options including EUS-RV procedures, EUS-CDS, EUS-HGS, EUS-guided antegrade stent placement, and EUS-GBD may be considered, whilst in malignant hilar obstruction only EUS-guided antegrade stent placement and EUSHGS are feasible alternatives. EUS-HGS can be complementary to ERCP in patients with an unresectable hilar stricture and inadequate drainage of the left hepatic duct [23, 33, 66, 67]. Similarly, EUS-guided hepaticoduodenostomy may aid in drainage of the right biliary system $[68,69]$. EUS-CDS, EUS-guided hepaticoduodenostomy and EUS-HGS have the additional benefit of the drainage point being distant from the malignant stricture, circumventing the risk of tumor ingrowth and offering the theoretical advantage of longer stent patency.

Experience with EUS-BD is growing. In addition to serving as rescue therapy, EUS-BD is now also being evaluated versus ERCP in ongoing randomized studies for primary biliary drainage in malignant distal biliary obstruction.

\subsubsection{What are the contraindications for EUS-BD?}

In some settings EUS-BD cannot be safely performed. These include the presence of intervening blood vessels and severe coagulopathy. Ascites may interfere with the trajectory of the needle and should also be regarded as a contraindication, as it is for percutaneous transhepatic biliary drainage (PTBD). In some patients, preprocedural drainage of ascites may be helpful to secure access to the biliary ducts [70]. If the bile ducts are not sufficiently dilated, that will also preclude the use of EUS-BD.

\subsection{Key question 4: How does EUS-BD compare with the alternative approaches?}

\subsubsection{Is EUS-BD preferable to PTBD after failed biliary drainage in distal malignant disease?}

\section{RECOMMENDATION}

ESGE recommends the use of EUS-guided biliary drainage over percutaneous transhepatic biliary drainage after failed ERCP in malignant distal biliary obstruction when local expertise is available.

Strong recommendation, moderate quality evidence.

PTBD is a widely available and efficient technique performed by interventional radiologists; however, it may be associated with significant morbidity [71]. Most available studies comparing EUS-BD and PTBD have included patients with distal malignant biliary obstruction. Small single-center, prospective or retrospective studies have shown comparable technical success (86\%-100\%), with similar or higher clinical success and fewer AEs, when using EUS-BD (Table 7s) [32,72-75]. In an RCT including 66 patients, comparable clinical success was accompanied by a significantly lower incidence of AEs in the EUS-BD cohort [76]. These results were further confirmed in a metaanalysis of nine studies including 483 patients, which demonstrated comparable technical success between EUS-BD and
PTBD, although EUS-BD was associated with higher clinical success and fewer AEs [77].

\subsubsection{Is EUS-BD preferable to PTBD after failed biliary drainage in proximal (hilar) malignant disease?}

\section{RECOMMENDATIONS}

ESGE recommends, for cases with malignant hilar biliary obstruction, multidisciplinary consultation to determine the most effective biliary drainage strategy, either as a bridge to surgery or as definitive palliative therapy. Strong recommendation, low quality evidence.

ESGE suggests EUS-guided biliary drainage with hepaticogastrostomy only for malignant inoperable hilar biliary obstruction with a dilated left hepatic duct when inadequately drained by ERCP and/or percutaneous transhepatic biliary drainage in high volume expert centers.

Weak recommendation, moderate quality evidence.

Endoscopic management of hilar strictures is challenging and should be performed in tertiary referral centers. It requires a thorough understanding of the anatomy, including anatomical variants, the extent of the disease, surgical resectability of the tumor, and the primary objective of biliary drainage (in preparation for surgery or as palliation). These complex situations require upfront discussions during multidisciplinary meetings involving interventional endoscopists, hepatopancreaticobiliary surgeons, digestive oncologists, and interventional radiologists to decide the optimal endoscopic biliary drainage strategy and avoid situations such as SEMS placement in potentially resectable settings or futile drainage of atrophic liver segments.

In complex Bismuth type III and IV strictures, the ESGE guidelines in 2017 recommended the use of PTBD over ERCP or a combination of PTBD and ERCP [78]. This recommendation was mainly based on a meta-analysis showing that PTBD obtained adequate biliary drainage more frequently than ERCP in these settings (odds ratio [OR] 2.53, 95\% Cl 1.57-4.08) [67]. Furthermore, in Bismuth type III and IV, drainage of more than $50 \%$ of the liver volume should be attempted, which often requires bilateral stenting or stenting of both right-sided anterior and posterior ducts to achieve this goal. However, ERCP remains frequently used for malignant hilar strictures and may have fewer AEs and achieve more complete biliary drainage in expert hands [79].

In unresectable malignant hilar strictures, EUS-BD is currently used as salvage therapy after previous metal stent placement. In addition, in surgically unresectable disease, even without previous biliary interventions, EUS-BD may be considered in addition to ERCP to optimize biliary drainage. Three retrospective studies have shown the efficacy of EUS-BD in malignant hilar biliary obstruction, with technical success rates exceeding $90 \%[23,33,80]$. One prospective, multicenter study compared a combination of ERCP and EUS-BD to bilateral PTBD in 36 
patients. The combined ERCP/EUS-BD approach provided a lower rate of recurrent biliary obstruction at 3 and 6 months, with similar AE and mortality rates [81].

\subsubsection{Is EUS-BD preferable to ERCP for primary biliary drainage in malignant distal biliary obstruction?}

\section{RECOMMENDATION}

ESGE recommends ERCP for primary drainage of malignant distal biliary obstruction, but EUS-guided biliary drainage could also be used in this setting for inoperable patients at high volume expert centers.

Strong recommendation, moderate quality evidence.

EUS-BD has been compared with ERCP in three RCTs for primary drainage of malignant distal biliary obstruction $[8,29$, 82]. Similar high technical and clinical success rates were reported, although the largest study showed fewer AEs and longer stent patency favoring EUS-BD (Table $8 \mathbf{s}$ ). All of the studies used SEMSs for both EUS-BD and ERCP. Ongoing RCTs are currently evaluating the use of LAMSs for EUS-BD in comparison to ERCP.

EUS-BD has not been reported to complicate subsequent surgical resection in patients with resectable tumors; however, only two retrospective studies, including a limited number of patients, have assessed the outcomes of preoperative LAMS placement on surgical outcome $[8,83]$. Because of the lack of quality evidence, EUS-BD cannot be advocated at present for primary biliary drainage in patients who will be considered for surgery or in borderline resectable patients, where surgery may still become an option following chemotherapy. In this setting ERCP should currently remain first-line therapy, but EUSBD can be considered if ERCP fails [78].

\subsubsection{Is EUS-BD preferable to repeat ERCP or PTBD}

after failed biliary cannulation in patients with benign

\section{RECOMMENDATION}

ESGE suggests an EUS-guided rendezvous technique after a second failed ERCP in benign biliary disease and normal gastrointestinal anatomy in high volume expert centers. Weak recommendation, low quality evidence.

Repeat ERCP in tertiary referral centers achieves high technical success $(75 \%-100 \%)$ and a low AE rate (3\%-8\%), and should be the first-line approach following failed ERCP [84, 85]. When repeat ERCP fails, alternatives include PTBD or EUS-BD. In benign biliary disease, EUS-RV is the preferred technique, provided that the bile ducts are sufficiently dilated, as it does not permanently alter the bilioenteric anatomy. The technical success of the EUS-RV technique in benign disease (77\%) is lower than in malignant disease ( $90 \%$ ) and AEs are more likely to occur (27\%), owing to limited bile duct dilatation and technical diffi- culty in accessing small intrahepatic ducts $[63,86]$. Although no comparative studies are currently available, PTBD is also challenging in patients with benign disease, leading to a significant $A E$ rate $(21 \%)$ and the frequent need for repeat procedures [71]. Therefore, EUS-BD should be considered after a second ERCP failure in centers where expertise is available, preferably during the same session.

\subsubsection{Is EUS-BD preferable to enteroscopy-assisted ERCP in patients with biliary obstruction and surgically altered anatomy?}

\section{RECOMMENDATIONS}

ESGE suggests EUS-guided biliary drainage (EUS-BD) only after failed enteroscopy-assisted ERCP in the management of benign post-surgical biliary obstruction or common bile duct stones.

Weak recommendation, low quality evidence.

ESGE suggests EUS-BD in malignant post-surgical biliary obstruction and a long biliary limb with dilated intrahepatic bile ducts.

Weak recommendation, low quality evidence.

In post-surgical anatomy, either a pediatric colonoscope or an enteroscope may be used to reach the papilla or surgical anastomosis, depending on the length of the biliary loop. Enteroscopy-assisted ERCP (EA-ERCP) is considered less invasive than EUS-BD and is associated with fewer AEs [87]. In addition, in EA-ERCP dedicated consumables are available that allow sphincterotomy and balloon extraction of stones. The drawbacks of EA-ERCP include difficulty in reaching the biliary orifice and lack of a scope elevator, as well as the limited diameter of the working channel of classic enteroscopes. Some recent enteroscopes have though been equipped with 3.2-mm working channels, which can facilitate SEMS placement.

Post-surgical malignant biliary obstruction normally comprises recurrence of malignant disease at the level of the surgical anastomosis. Under these circumstances EUS-guided antegrade stenting or HGS is technically successful in 96\%-100\% of cases and allows the placement of SEMSs $[27,88]$.

In benign disease, owing to the aforementioned advantages, including lower $A E$ rate and the availability of dedicated consumables, EA-ERCP may be preferred over EUS-BD as the initial approach. This is especially relevant in the setting of biliary stone disease, where a biliary sphincterotomy will be required [87]. EUS-BD procedures in benign biliary diseases are more complex than in the management of malignant disease. Nevertheless, EUS-BD facilitates stricture dilation and stone clearance in $72 \%-100 \%$ of patients [89-91], and is therefore a reasonable alternative after failed EA-ERCP in patients with benign biliary obstruction and post-surgical anatomy. 


\subsection{Key question 5: What are the most common adverse events associated with EUS-BD?}

RECOMMENDATION

ESGE suggests that current evidence supports the use of EUS-guided choledochoduodenostomy over EUS-guided hepaticogastrostomy in distal biliary obstruction owing to its lower rate of adverse events.

Weak recommendation, low quality evidence.

Complications following EUS-BD are usually reported as procedure-related, early (<14 days), or late (>14 days) AEs [92]. AEs in EUS-BD occur most commonly following transmural puncture, which can result in either trauma to blood vessels or leakage of $\mathrm{Gl}$ and/or biliary contents. In addition, stent maldeployment during the procedure or stent dislodgement after the procedure may be associated with spillage of bile and GI secretions into the peritoneal cavity or retroperitoneal space. This risk, has been mitigated to some extent by newer stent designs. It should be noted that large volume or recurrent ascites increases the risk for AEs $[93,94]$.

Pooled AE rates for EUS-BD (EUS-CDS and EUS-HGS combined) were $16 \%$ in a meta-analysis of 756 patients [95]. For EUS-CDS alone, a meta-analysis of 572 patients reported a pooled rate of $14 \%$, the most common AEs being cholangitis (4\%), bleeding (4\%), bile leak (4\%), and perforation (3\%) [94]. Abdominal pain occurred commonly (up to $18 \%$ ) but was usually mild [33]. Also rarely reported were pneumoperitoneum, hemobilia, cholecystitis, arteriobiliary fistula, pseudoaneurysm, and inadvertent portal vein puncture [30,35, 93, 94, 96, 97]. Mortality ranged from $0 \%$ to $3 \%$ [96]. Poincloux et al. reported a high mortality of $6 \%$; however, the mortality rate was lower in the second 50 cases compared with the first (decreasing from $10 \%$ to $2 \%$ ), suggesting a learning curve effect [30]. The most common long-term AE is stent occlusion, with the median time of occurrence ranging from 5 to 12 months $[30,93,96]$. This can often be resolved during a second procedure, either by stent-in-stent placement or drainage of alternative segments $[33,93]$.

In a randomized trial of 125 patients comparing EUS-BD with ERCP as a primary intervention, there was a lower rate of procedure-related and late AEs in EUS-BD (6\% vs. $19 \%$ [P=0.001]; $4 \%$ vs. $19 \%[P=0.01])$ respectively [29]. The increase in procedurerelated $\mathrm{AEs}$ was mostly due to pancreatitis in the ERCP group, although rectal NSAIDs were not administered in this study. In addition, there was a higher rate of stent patency at 6 months ( $85 \%$ vs. $49 \% ; P=0.001$ ) and a longer mean stent patency time (208 vs. 165 days) when using EUS-BD. In contrast, two metaanalyses, incorporating three randomized trials and additional non-randomized cohort comparisons, failed to demonstrate a significant difference between EUS-BD and ERCP (relative risk (RR) 0.68 and 1.05 , respectively) $[95,98]$. In these two analyses, EUS-BD was associated with significantly lower rates of post-procedural pancreatitis (RR 0.12 and 0.26 ), which was at least in part offset by higher rates of biliary peritonitis, bleeding, and pneumoperitoneum (RR 5.16) [95]. However, EUS-BD was associated with higher long-term stent patency compared with ERCP [98].

In two meta-analyses, the pooled AE rates for EUS-CDS were lower than for EUS-HGS, but this only reached clinical significance in one study (15\% vs. $21 \%$; $P=0.1$ and $20 \%$ vs. $29 \% ; P=0.01)[35,94]$. Two older meta-analyses reported either no difference in $A E$ rates between EUS-CDS and EUSHGS or a reduced AE rate in EUS-CDS (OR 0.40) [36, 37].

For EUS-RV procedures, reported AE rates range from $13 \%$ to $34 \%$, with higher rates following intrahepatic puncture $[47,49]$. Post-procedural pain is most commonly observed, with other AEs including pneumoperitoneum or pneumomediastinum also being described [99]. Cholangitis, peritonitis, and bleeding were all reported infrequently. Pancreatitis occurred in $2 \%-5 \%[49,60,99]$. Mortality was infrequently reported and ranged from $0 \%$ to $10 \%[27,47,49,50,60,99,100]$.

\subsection{Key question 6: What are the main approaches that employ EUS to achieve PD drainage?}

EUS-guided PD drainage may be considered in the management of symptomatic PD obstruction when conventional endoscopic methods have failed, and in patients who are not considered surgical candidates or, prefer a minimally invasive approach $[101,102]$.

EUS-guided PD drainage can be considered a salvage procedure after technical failure of endoscopic retrograde pancreatography (ERP) or as an alternative to enteroscopy-assisted ERP (EA-ERP) in patients with surgically altered anatomy [103].

There are two main approaches that are used for EUS-guided PD drainage. Rendezvous-assisted ERP (RV-ERP), similarly to biliary EUS-RV techniques, requires antegrade transpapillary/ transanastomotic passage of a guidewire to enable cannulation of the main pancreatic duct (MPD) via ERP [104, 105].

The second approach, transmural or antegrade EUS-guided PD drainage is considered when RV-ERP either fails or is not technically feasible. This technique involves the transmural passage of a pancreatic stent, directly through the lumen wall (gastric or enteral), following creation of a fistulous tract into the MPD. The pancreatic stent may then be advanced in an antegrade fashion across either the papilla or surgical anastomosis, or alternatively it may be deployed transmurally into the stomach or small bowel. Variations of EUS-guided PD drainage include: pancreaticogastrostomy, pancreaticoenterostomy, gastropancreaticoenterostomy (also known as ring drainage), and pancreaticobulbostomy. 


\subsection{Key question 7: What are the technical and clinical success rates of each approach?}

\section{RECOMMENDATIONS}

ESGE recommends that EUS-guided pancreatic duct (PD) drainage should only be considered in symptomatic patients with an obstructed PD when retrograde endoscopic intervention fails or is not possible.

Strong recommendation, low quality evidence.

ESGE recommends that EUS-guided PD drainage should only be performed in high volume expert centers owing to the complexity of this technique and the high risk of adverse events associated with it.

Strong recommendation, low quality evidence.

ESGE recommends rendezvous EUS techniques over transmural PD drainage in patients with favorable anatomy owing to its lower rate of adverse events.

Strong recommendation, low quality evidence.

RV-ERP is preferable to transmural EUS-guided PD drainage as the underlying pathology associated with chronic pancreatitis, such as the presence of an MPD stricture or stones, can be more effectively managed using a retrograde approach. Also, RV-ERP allows physiologic drainage of pancreatic secretions across the papilla or surgical anastomosis, rather than through a fistulous tract [106]. Additionally, the use of RV-ERP avoids the need to use thermal energy and/or balloon dilation of the tract during creation of a pancreaticogastric fistula, thereby decreasing the number of AEs, including leakage of gastric or pancreatic content into the retroperitoneal space $[103,104]$.

EUS-guided PD drainage is technically challenging, has limited indications, and is generally performed at select high volume centers, therefore only small series have been reported. Technical contraindications for EUS-guided PD drainage include the inability to localize the MPD endosonographically, the presence of significant intervening vasculature in the intended puncture path, and there being multiple MPD strictures [104, 107, 108].

The definition of technical success in EUS-guided PD drainage has differed according to the reported series, with end points such as obtaining a pancreatogram, PD cannulation, PD stenting and/or drainage, or stricture dilation, and/or stent placement included [109]. However, in the context of EUSguided PD drainage, technical success is best defined as successful stent placement, while clinical success should be defined as pain relief, using a visual analogue score, that may be subcategorized as partial or complete.

Since Francois et al. first reported the pancreaticogastrostomy procedure approximately two decades ago, there have been several retrospective and fewer prospective series of EUS-guided PD drainage with modest numbers [110]. The overall technical success of antegrade drainage was 138/155 (89\%)
[104]. Few prospective studies have evaluated EUS-PD. Kahaleh et al. described successful pancreaticogastrostomy in 10/13 patients with symptomatic chronic pancreatitis after failed ERP [111]. Follow-up at 14 months showed the average MPD caliber significantly decreased and pain scores improved. An additional study, using a fully covered SEMS, in 25 patients with chronic pancreatitis and ductal obstruction after failed ERP also demonstrated significant improvement in their pain scores [112].

\subsection{Key question 8: What are the indications for EUS-guided PD drainage?}

In patients with MPD obstruction and normal anatomy, ERP remains the preferred method of endoscopic drainage. ERP transpapillary therapy fails in 3\%-10\% of cases owing to complete PD obstruction and/or disconnection of the MPD [113]. Only when ERP fails, and surgery is undesirable or excessively high risk, should alternative endoscopic therapies such as EUS-guided PD drainage or EA-ERP (in surgically altered anatomy) be considered. Complete PD obstruction by a large PD stone is better managed by extracorporeal shock wave lithotripsy or surgery.

The aim of EUS-guided PD drainage is to relieve the ductal hypertension that is responsible for pain or recurrent acute pancreatitis in patients with a dilated MPD. The primary indication for EUS-guided PD drainage is an inaccessible papilla or failed papillary cannulation of the PD [104,106,111,114116]. This frequently arises in patients with symptomatic chronic pancreatitis with a tight ductal stricture, disconnected PD, or pancreaticojejunostomy anastomotic stricture following pancreaticoduodenectomy. EUS-guided PD drainage can be considered if surgical drainage carries an unacceptable risk, as surgery provides better long-term symptomatic benefit than endoscopic decompression. EUS-guided PD drainage can also be considered for patients desiring a minimally invasive approach $[101,102]$. If both EUS-guided PD drainage approaches are technically feasible, RV-ERP should be considered in preference to antegrade or transmural drainage [105].

\subsubsection{What are the contraindications for EUS-guided PD drainage?}

In some instances, EUS-guided PD drainage may be contraindicated, including inability to localize the MPD endosonographically or when the PD is not sufficiently dilated, as well as the presence of significant intervening vasculature in the intended puncture path, and multiple MPD strictures [104, 107, 108].

\subsection{Key question 9: How does EUS-guided PD drain- age compare with the alternative approaches?}

\subsubsection{How does EUS-guided PD drainage compare with enteroscopy-assisted ERP?}

Until recently, before the development of therapeutic EUS and the implementation of EUS-guided PD drainage, EA-ERP was considered an option to manage symptomatic patients after pancreaticoduodenectomy with anastomotic strictures and a dilated MPD. If EA-ERP was not possible, a redo surgical intervention remained the only alternative [104]. 
EA-ERP is reasonably safe with widespread procedural familiarity [103]. However, the reported technical success rate may be as low as $8 \%$ [117]. Therefore, nowadays EUS-guided PD drainage is often preferred instead of EA-ERP. Chen et al. compared EUS-guided PD drainage to EA-ERP following pancreaticoduodenectomy [103]. Their study compared 43 patients who underwent EUS-guided PD drainage (antegrade/transmural in 40 patients; RV-ERP in 3 patients) to 35 patients who underwent EA-ERP. EUS-guided PD drainage was found to be superior to EA-ERP, both in terms of technical success $(92.5 \%$ vs. $20 \%$; $P<0.001)$ and clinical success $(87.5 \%$ vs. $23.1 \%$; $P<0.001)$. EA-ERP was associated with fewer AEs than EUSguided PD drainage ( $2.9 \%$ vs. $37.5 \% ; P<0.001)$, although no serious AEs occurred in either group.

\subsubsection{How does EUS-guided PD drainage compare with ERP in pancreaticojejunostomy?}

A recent systematic review compared the outcomes of ERP to EUS-guided PD drainage in patients with pancreaticojejunostomy strictures [109]. This study included 13 studies, in which 77 patients underwent ERP-guided drainage, 145 patients EUSguided drainage, and 12 patients underwent both modalities. An EUS-guided approach was significantly superior to ERP regarding technical parameters, such as PD opacification $(87 \%$ vs. $30 \%$; $P<0.001)$, cannulation success (79\% vs. $26 \%$; $P<0.001)$, and stent placement $(72 \%$ vs. $20 \%$; $P<0.001)$. The EUS-guided approach also appeared superior in terms of pain resolution. There are no comparative trials of EUS-guided PD drainage versus surgical intervention.

\subsection{Key question 10: What are the most common adverse events associated with EUS-guided PD drainage?}

EUS-guided PD drainage is one of the most technically challenging and risky endoscopic procedures currently performed. Available data on the AEs of EUS-guided PD drainage suggest that the overall AE rate varies from 15\%-27\% [104, 118-120]. The data are however extremely heterogeneous and difficult to interpret. The current literature frequently pools dissimilar patients (e.g. native anatomy and surgically altered anatomy), equipment (e.g. thermal and non-thermal ductal access), and procedural techniques (e.g. EUS-guided pancreatic rendezvous and EUS-guided pancreaticogastrostomy), therefore leading to difficulty in interpretation.

A recent systematic review (13 studies, 409 patients), showed the overall AE rate of EUS-guided PD drainage to be $15 \%$ [109]. No significant differences were noted with respect to $A E$ rates of EUS-guided $P D$ drainage when comparing patients with native pancreatic anatomy to those with surgically altered pancreatic anatomy (15\% vs. $11 \%)$. The most commonly reported AEs included: post-procedure pain (7\%), acute pancreatitis (2\%), infected peripancreatic collections (2\%), and perforation ( $1 \%$ ). Less commonly reported AEs, occurring in $<1 \%$ of patients, included bleeding, PD leakage, and pseudoaneurysm formation. AE rates were higher in EUS-guided transmural pancreaticogastrostomy compared with RV-ERP [104, 118-120]. In one study using a fully covered SEMS in 25 patients with chronic pancreatitis with ductal obstruction after failed ERP, no major AEs (i.e. stent migration, stent dysfunction, infection, and/or stent-induced ductal stricture) occurred during follow-up of over 7 months [112].

\section{Gallbladder drainage}

Laparoscopic cholecystectomy represents the gold standard treatment in the management of acute cholecystitis and is associated with low postoperative morbidity and shorter length of hospital stay compared with open surgery [121, 122]. However, owing to advanced age, frailty, or co-morbidities, some patients may not initially be, or may never become, surgical candidates. In these patients, especially when they are at risk for developing sepsis and organ failure, gallbladder drainage may be required. This has traditionally been provided by the percutaneous approach. In recent years, EUS-GBD has become an alternative to percutaneous gallbladder drainage (PTGBD).

\subsection{Key question 11: What are the main approaches that employ EUS to achieve gallbladder drainage?}

EUS-GBD may be performed using a transgastric or transduodenal approach. The transduodenal approach is most commonly used because the position of the stent is less affected by peristalsis, than if deployed in the distal stomach. In addition, the risk of food impaction with a stent placed in the duodenum may be lower $[123,124]$. In patients who may be considered for cholecystectomy in the future, a transgastric approach may be more favorable because the surgical repair of a gastric wall defect is less complex [124].

\subsection{Key question 12: What are the technical and clinical success rates of EUS-GBD?}

A multicenter prospective study reported the outcomes of EUSGBD using LAMSs in 30 high risk surgical patients with acute cholecystitis [125]. In this study, technical and clinical success were $90 \%$ and $87 \%$, respectively. Cholecystitis due to LAMS occlusion occurred in $7 \%$ of patients. Another retrospective study reported the use of EUS-GBD using SEMSs in 63 patients with acute cholecystitis, who were unsuitable for cholecystectomy owing to high surgical risk or advanced malignancy, and showed a technical success rate of $98 \%$ and a clinical success rate of $95 \%$ [126].

A meta-analysis, including 233 patients from 13 studies using LAMSs in high risk surgical patients with acute cholecystitis or biliary obstruction, showed that the technical and clinical success, and overall AE rates of EUS-GBD were $94 \%, 93 \%$, and $18 \%$, respectively [127] (Table 9 s). 


\subsection{Key question 13: What are the indications for EUS-GBD?}

\section{RECOMMENDATION}

ESGE suggests that EUS-guided gallbladder drainage can be considered as a rescue procedure in patients with inoperable distal malignant biliary obstruction when ERCP and EUS-biliary drainage have failed, provided that the cystic duct is patent.

Weak recommendation, low quality of evidence.

Since its introduction, many studies have reported the feasibility, safety, and effectiveness of EUS-GBD compared with PTGBD in patients with acute cholecystitis. Specifically, EUSGBD has been associated with fewer re-interventions and readmissions compared with PTGBD, when performed in tertiary centers experienced in advanced therapeutic EUS. However, many of these studies were limited by their retrospective design, low patient numbers, potential publication bias, and variable technical approaches (LAMS vs. SEMS vs. plastic stents) $[125,126,128-130]$.

As previously mentioned, EUS-GBD has also been used as a rescue strategy for biliary drainage in distal malignant biliary obstruction. Data on the efficacy and outcome of EUS-GBD in this setting are limited. Imai et al. demonstrated, in a retrospective study, that EUS-GBD with fully covered SEMS placement was safe and efficient after failed ERCP or unsuccessful EUS-BD in patients with inoperable distal biliary malignancy [55]. They reported that, in 12 patients, the technical and clinical success, $A E$, and stent dysfunction rates were $100 \%, 92 \%$, $17 \%$, and $8 \%$, respectively. Early AEs occurred in two patients and included peritonitis and stent dysfunction (entrapment of the cystic duct by the growing tumor). A median survival time after the procedure of 105 days (range 15-236 days) was observed [55]. Other authors have retrospectively reported EUSGBD with LAMS placement as the first intervention in nine patients with malignant distal biliary obstruction and showed technical success, clinical success, and AE rates of $100 \%, 78 \%$, and $0 \%$ respectively [131]. Although these studies suggest that EUS-GBD can be considered as a rescue procedure when ERCP or EUS has failed, special care should be taken to confirm cystic duct patency before using this strategy.

\subsection{Key question 14: How does EUS-GBD compare with the alternative approaches?}

\subsubsection{How does EUS-GBD compare with PTGBD?}

\section{RECOMMENDATIONS}

ESGE recommends EUS-guided gallbladder drainage (EUS-GBD) or percutaneous gallbladder drainage (PTGBD) in patients at high surgical risk with acute cholecystitis requiring gallbladder drainage.

Strong recommendation, high quality of evidence.

ESGE recommends that, in patients at high surgical risk, EUS-GBD should be favored over PTGBD where both techniques are available, owing to the lower rates of AEs and need for re-intervention in EUS-GBD.

Strong recommendation, high quality of evidence.

EUS-GBD seems to be an effective alternative to PTGBD in high risk surgical patients. Studies that have compared EUSGBD with PTGBD have shown comparable technical and clinical success rates, and fewer AEs following EUS-GBD. An RCT designed to compare EUS-GBD with PTGBD in 59 high risk patients with acute cholecystitis showed comparable results for both procedures with respect to technical feasibility and AEs [132]. Another RCT showed significantly better outcomes in very high risk patients who were unfit for cholecystectomy who underwent EUS-GBD compared with those who underwent PTGBD [133]. This study performed in 80 patients showed that EUS-GBD significantly reduced the 30-day and 1-year AE rates, led to fewer re-interventions after 30 days, and reduced the rates of unplanned readmission and recurrent cholecystitis.

A recent meta-analysis comparing EUS-GBD to PTGBD for the management of acute cholecystitis in 495 patients reported no statistically significant differences in terms of technical and clinical success rates between these two techniques. However, significantly lower post-procedural pain scores and re-intervention rates were observed in the EUS-GBD group [134]. Data have also shown that EUS-GBD may be used as a bridge to surgery [135]. Finally, larger comparative studies are needed to confirm these results.

\subsubsection{How does EUS-GBD compare with transpapillary gallbladder drainage?}

\section{RECOMMENDATION}

ESGE recommends EUS-guided gallbladder drainage over transpapillary gallbladder drainage, given the suboptimal technical efficacy of transpapillary gallbladder drainage. Strong recommendation, low quality of evidence. 
EUS-GBD has also been compared with transpapillary gallbladder drainage in patients with acute cholecystitis who cannot undergo surgery $[123,133,136]$. A multicenter retrospective study compared EUS-GBD using LAMSs, PTGBD, and transpapillary gallbladder drainage in high risk surgical patients with acute cholecystitis. Technical success was achieved in $88 \%, 94 \%$, and $98 \%$, respectively $(P=0.004)$, whilst clinical success rates were lower with transpapillary gallbladder drainage compared with EUS-GBD and PTGBD (80\%, $90 \%$, and $97 \%$, respectively; $P<0.001)$. Fewer overall AEs ( $2 \%$ vs. $5 \%$ vs. $20 \%$; $P=0.01)$, shorter hospital stay ( 16 vs. 18 vs. 19 days; $P=0.01$ ), and fewer unplanned admissions ( $4 \%$ vs. $11 \%$ vs. $49 \%$; $P<0.001$ ) were observed with EUS-GBD and transpapillary gallbladder drainage compared with PTGBD [137]. A meta-analysis of 857 high risk surgical patients with acute cholecystitis comparing EUS-GBD with transpapillary gallbladder drainage showed higher technical and clinical success rates with EUS-GBD. A lower rate of recurrent cholecystitis was shown with EUS-GBD, while there was no statistically significant difference in terms of overall $A E$ rates between the two procedures [138].

\subsection{Key question 15: What are the most common adverse events associated with EUS-GBD?}

A multicenter prospective study reported cholecystitis due to LAMS occlusion in $7 \%$ of patients [125]. Another retrospective study showed that AEs, such as duodenal perforation (1.6\%) and small pneumoperitoneum (3.2\%), occurred infrequently and resolved with conservative treatment [126]. The longterm outcomes were favorable, with inconsequential distal stent migration and acute cholecystitis due to stent occlusion occurring in four patients $(7.1 \%)$ during a median follow-up of 275 days (range 40-1185 days). Stent occlusions were successfully treated endoscopically, with a re-intervention rate of $3.6 \%$ and a cumulative stent patency rate of $86 \%$ at 3 years.

A meta-analysis, including 233 patients from 13 studies using LAMSs in high risk surgical patients with acute cholecystitis or biliary obstruction, showed stent obstruction or dislodgement, perforations, and recurrent cholangitis/cholecystitis in $8 \%, 7 \%$, and $4 \%$ of patients, respectively [127]. A pooled analysis of 166 patients reported an overall $A E$ rate of $12 \%$ [123].

\section{EUS-guided gastrointestinal anastomosis}

RECOMMENDATION

ESGE recommends multidisciplinary discussion of all patients being considered for an EUS-guided gastrointestinal anastomosis and careful evaluation for adverse events after the procedure.

Strong recommendation, low quality evidence.

EUS-guided GI anastomosis refers to a technique where the walls of two luminal structures are apposed by the placement of a LAMS under EUS guidance. By placement of this dumbbell- shaped fully covered SEMS, fusion of the individual layers occurs, turning into a mature anastomosis within days. Procedures where this concept applies include EUS-guided gastroenterostomy (EUS-GE), where a LAMS is placed between the stomach and a duodenal or jejunal loop to circumvent a gastric outlet obstruction (GOO), or gastro-gastrostomy, where a LAMS is placed between the gastric pouch and excluded stomach for access following Roux-en-Y gastric bypass (RYGB). These procedures should be performed by trained interventional endoscopists capable of recognizing and endoscopically managing procedure-related AEs.

\subsection{Key question 16: What are the main approaches that employ EUS to create a gastroenterostomy?}

Various techniques have been developed to create an EUS-GE, with the aim of overcoming two main challenges: (a) locating the segment distal to the GOO; and (b) stabilizing the targeted loop for subsequent puncture and stent introduction.

\subsubsection{Direct EUS-GE technique over a guidewire}

A linear echoendoscope is used to visualize the saline-filled duodenum or jejunum. A transgastric puncture is performed with a 19G FNA needle and a guidewire is advanced into the target small bowel. The electrocautery-tipped delivery device is advanced over the guidewire and the distal flange is deployed under EUS guidance. The device is then gently retracted, approximating the small bowel to the gastric wall, before the proximal flange is released under endoscopic and fluoroscopic guidance.

\subsubsection{Wireless endoscopic simplified technique}

After the small bowel distal to the GOO has been filled with saline, a linear echoendoscope is advanced into the stomach. After the saline-filled small bowel target has been located, the electrocautery tip is advanced directly, using a free-hand technique under endosonographic control, without the aid of a guidewire or confirmatory 19G FNA needle puncture. The same steps for deployment are followed to release the stent as for the overthe-guidewire technique [139, 140].

\subsubsection{Assisted EUS-GE technique}

Assisted EUS-GE techniques refer to approaches using dilation balloons, stone extraction balloons, or double-balloon enteroscopes [141-143]. In the balloon-assisted techniques, a guidewire is inserted across the malignant GOO and the balloon catheter is advanced under fluoroscopic guidance into the jejunum. Under EUS guidance, the fluid-filled balloon or occluded jejunal segment is punctured with a 19G FNA needle and a guidewire is advanced into the jejunal lumen. A LAMS is then inserted and deployed over the guidewire, similarly to the direct technique.

\subsection{Key question 17: What are the technical and clinical success rates of EUS-GE?}

Technical success does not seem to differ according to technique, ranging from $92 \%$ to $100 \%$ [144]. The overall technical success rate was $94 \%$, with $68 \%$ of the procedures being performed by the direct EUS-GE approach, in a meta-analysis 
including 12 studies and 290 patients [144]. Assisted EUS-GE could potentially decrease the rate of stent dislodgement or misdeployment. This however was not demonstrated in a recent comparative study comparing direct EUS-GE with the assisted technique, which reported success rates of $94 \%$ vs. $95 \%$, respectively, with comparable safety but a shorter procedural time for the direct method (30 vs. 90 minutes) [145].

\subsubsection{Which EUS-guided technique is superior in creating a gastroenterostomy?}

Technical success is similar between the various techniques for creating an EUS-GE [144] (Table10s). A recently published study using the wireless endoscopic simplified technique (WEST) showed high procedural success and a low AE rate, suggesting that the additional use of balloons or maneuvers aimed at stabilizing the target loop may not be required $[139,140]$. While no high quality prospective comparison exists, most data and experience originate from reports of cohorts using the direct method or WEST [140, 145-148].

\subsection{Key question 18: What are the indications for EUS-GE?}

\subsubsection{EUS-GE in malignant gastric outlet obstruction}

The most widely accepted indication for EUS-GE is malignant GOO. This is most often caused by pancreatic, gastric, ampullary, or biliary/gallbladder cancers that infiltrate or cause external compression of the duodenum, preventing transit of solids and eventually fluids to the distal small bowel $[149,150]$. In the event of locally advanced or metastatic disease, where surgical resection is not an option, appropriate management of obstructive symptoms is justified to optimize the patient's nutritional status and improve their quality of life [151].

Traditionally, treatment options for GOO have consisted of surgical (open/laparoscopic) gastrojejunostomy or endoscopic placement of an enteral SEMS. Three underpowered RCTs comparing these approaches have reached inconsistent results [152-154]. Surgical bypass has been demonstrated to achieve better long-term outcomes, at the cost of increased invasiveness and prolonged hospital stay. Conversely, enteral stenting provided rapid resumption of oral intake, yet showed a high rate of symptom recurrence requiring re-intervention [152155]. This has led various authors to suggest that enteral stenting should be reserved for patients with a short life expectancy of less than 3 months $[153,156]$.

EUS-GE may combine the theoretical advantages of both of these approaches, creating a relatively large gastroenteric anastomosis, while using a minimally invasive technique at a distance from the primary tumor. Results from clinical experience with this technique are detailed in Table 7 s. Published cohorts of more than 10 cases have been described in 15 studies (with partial cohort overlap), all but one of these being retrospective $[140,145-149,157-165]$. The results from these studies were included in five recent pooled analyses and systematic reviews including almost 300 patients [144, 166-169]. The technical and clinical success rates of EUS-GE are reported to range from $91 \%$ to $94 \%$ and $88 \%$ to $90 \%$, respectively [ 147 ,
164]. AE rates were reported as between $7 \%$ and $12 \%$, with AEs encompassing abdominal pain, bleeding, infections, perforations, and leakage from the EUS-GE site.

\subsubsection{Is there a role for EUS-GE in benign gastric outlet obstruction?}

RECOMMENDATIONS

ESGE suggests that an EUS-guided gastroenterostomy be created for patients who are poor surgical candidates with refractory benign gastric outlet obstruction (GOO). Weak recommendation, low quality evidence.

ESGE recommends that, upon resolution of the cause of the benign $\mathrm{GOO}$, the lumen-apposing metal stent should be removed.

Strong recommendation, low quality evidence.

EUS-GE has also been used in benign GOO, for instance in patients with chronic pancreatitis, peptic ulcer disease, caustic injury, or even superior mesenteric artery syndrome [140, 148, 170-172]. In benign GOO, endoscopic balloon dilation has been used as an alternative to surgery; however, it often results in suboptimal outcomes, with early recurrence of symptoms, and is associated with a non-negligible risk of perforation $[173,174]$. Because some of these patients are poor surgical candidates, EUS-GE has been proposed as an alternative to surgery.

One argument against the use of EUS-GE in benign GOO has been the lack of long-term data. A recent pooled analysis has shown a mean (SD) LAMS indwelling time of 88 (33) days. In this study, LAMS placement was associated with a low risk of symptom recurrence due to food obstruction. If food impaction occurred, it could be easily resolved endoscopically (10\%) [159, $161,169]$. The most frequent AE identified that needed revision was ulceration at the stent site [169]. As a general principle, LAMSs should be removed once the underlying disease has resolved. In patients with persistent non-resolving duodenal obstruction, LAMS patency should be assessed over time, facilitating timely exchange when indicated.

Two recent studies specifically included only patients with benign GOO for which LAMSs were placed $[148,157]$. In the most recent, 22 patients were included [148]. LAMS placement was successful in 21 cases. During follow-up, GOO recurred in five patients with a LAMS in place $(23 \%)$ after a mean dwell time of 228 days. LAMSs were electively removed in 18 patients after resolution of the GOO, and the recurrence rate after LAMS removal was $6 \%$. In this cohort of patients with benign GOO, surgery was prevented in $83 \%$ of cases. When surgery was eventually required, it was executed after a mean of 270 days. The data suggest that EUS-GE has the potential to obviate the need for surgery in many of these patients, while potentially providing a bridge toward safer surgery in others owing to the restoration of adequate nutritional status. Further studies are 
needed to clarify the role of EUS-GE in the management of benign GOO.

\subsubsection{Is there a role for EUS-GE in afferent loop syndrome?}

\section{RECOMMENDATION}

ESGE recommends that EUS-guided gastroenterostomy may be considered in the management of afferent loop syndrome, especially in the setting of malignancy or in poor surgical candidates.

Strong recommendation, low quality evidence.

EUS-guided anastomoses have also been used in the management of afferent loop syndrome, following pancreaticoduodenectomy, Roux-en-Y hepaticojejunostomy, or Billroth II gastrectomy. This clinical entity may be caused by a benign stenosis, such as visceral adhesions, radiation enteritis, kinking of the small bowel, internal hernias, or recurrence of malignant disease, and can present as jaundice, with or without cholangitis and/or abdominal pain, nausea, and vomiting. In these circumstances, a minimally invasive alternative is desirable as surgery may be challenging and percutaneous biliary drainage has notable drawbacks.

The dilated and bile-filled obstructed loop can be identified by the echoendoscope placed in an adjacent lumen, either the stomach, duodenum, or proximal jejunum, and drained through placement of a LAMS. Multiple case reports and some small retrospective case series have described this procedure [175-179]. The largest published series to date (retrospective, multicenter, $n=18$ ), which used mainly LAMSs of $15 \mathrm{~mm}$ in diameter, showed $100 \%$ technical success and clinical improvement rates ( $89 \%$ complete resolution), with re-intervention required in $17 \%$ of patients [175]. The rates of clinical success and re-intervention were significantly better than those of a control group who underwent enteroscopy-assisted luminal stenting. Given the relative rarity of afferent loop syndrome, it is unlikely that high quality prospective studies will be performed. With the current retrospective data in mind, EUS-GE seems a safe and effective approach in treating afferent loop obstruction.

\subsubsection{What are the contraindications for EUS-GE?}

\section{RECOMMENDATION}

ESGE recommends that, in gastric outlet obstruction, EUS-guided gastroenterostomy should not be performed in the presence of significant malignant or refractory ascites, diffuse malignant infiltration of the gastric wall, or extensive peritoneal carcinomatosis.

Strong recommendation, low quality evidence.

The classic contraindications for interventional endoscopic procedures, such as uncontrolled coagulopathy, apply to EUSGE. As EUS-GE is often used in the setting of malignancy, manifestations of advanced tumor burden should be actively excluded before EUS-GE is considered.

Several authors have reported the use of EUS-GE in patients with ascites $[140,180]$. However, the presence of ascites is often reflective of the extent of malignant involvement of the peritoneum. Patients with malignant ascites due to high peritoneal tumor burden are also those who have the lowest expected benefit from EUS-GE. In addition, the presence of ascites may also be reflective of diffuse peritoneal tumor implants and additional sites of obstruction may be "unmasked" by creation of an EUS-GE. Lastly, if the FNA needle or electrocautery catheter tip have to traverse through ascites, it introduces an additional risk of infection [140]. A small amount of ascites is not considered a contraindication for EUS-GE but a longer duration of prophylactic antibiotics will be required.

EUS-GE should be avoided in patients with extensive malignant infiltration of the gastric wall because of the potential negative effects on gastric motility and an increased need for cutting current, which may increase the post-procedure bleeding risk.

\subsection{Key question 19: How does EUS-GE compare with the alternative approaches?}

\subsubsection{How does EUS-GE compare with surgical gastro- enterostomy and duodenal stenting in malignant GOO?}

\section{RECOMMENDATION}

ESGE recommends EUS-GE, performed in an expert setting, for malignant gastric outlet obstruction, as an alternative to enteral stenting or surgery.

Strong recommendation, low quality evidence.

Among the four studies that have compared EUS-GE to surgery, EUS-GE systematically showed shorter time to oral intake, time to chemotherapy initiation, hospital stay, and reduced costs, while significantly more AEs were seen in patients who underwent surgery $[140,146,147,163]$. In two studies that compared EUS-GE with enteral stenting, higher clinical success rates were seen in the EUS-GE group, who also had a lower risk of recurrent obstruction and less need for re-intervention [149, 180].

Based mostly on retrospective comparative data, EUS-GE seems, in the expert setting, to be a valuable alternative to surgery and enteral stenting for the management of GOO. RCTs are currently underway to provide high quality confirmation of these results.

\subsection{Key question 20: What are the most common adverse events associated with EUS-GE?}

Potential procedural-related AEs that have been described include: (i) stent maldeployment resulting in perforation [147] or leakage $[157,161]$ with peritonitis; (ii) stent misplacement; (iii) stent migration or dislodgement; (iv) bleeding (intraluminal, intramural, or intraperitoneal) $[147,148,161,181]$; and (v) 
anesthesia-related AEs, including aspiration of gastric contents in the setting of GOO [163]. Among post-procedural AEs, the most common include abdominal pain $[146,149]$ and erosion/ ulceration of the contralateral wall due to the mesh of the stent [180]. Systematic reviews and meta-analyses on EUS-GE have reported periprocedural AEs in $11 \%-12 \%$ of patients [ 144 , $167,168]$. Most of the reported AEs were graded as mild or moderately severe, although severe or even fatal AEs occurred in $2.9 \%-5.6 \%$ of cases.

Stent maldeployment can be adequately managed by endoscopy in the large majority of cases, reducing the likelihood of severe AEs, such as peritonitis, and/or death [147, 164, 182]. Long-term AEs in patients with EUS-guided lumento-lumen anastomoses include stent migration $[148,183$, 184], obstruction by food residue [148], and tissue ingrowth [180] or overgrowth [145].

\section{Biliary drainage in patients who have undergone Roux-en-Y gastric bypass}

\subsection{Key question 21: How can biliary drainage be achieved using EUS-guided gastro-gastrostomy in patients following Roux-en-Y gastric bypass?}

Patients are more prone to biliary disease following RYGB and conventional ERCP using a duodenoscope is not possible following this type of surgery. Various techniques have been developed to achieve biliary drainage in this setting.

A combined surgical/endoscopic approach may be used, commonly referred to as laparoscopy-assisted ERCP (LA-ERCP). In this procedure, temporary access to the bile duct is created through a surgical port, allowing the duodenoscope to be inserted into the stomach and advanced to the papilla. This approach is often chosen when ERCP needs to be combined with same-session laparoscopic cholecystectomy.

The papilla may also be accessed by using a single- or doubleballoon enteroscope, which is advanced up to the biliary limb and eventually up to the level of the papilla. This technique (EA-ERCP) has some disadvantages. It may be extremely cumbersome to advance the enteroscope and the endoscopist may ultimately fail to reach the papilla in up to $30 \%$ of patients. In addition, cannulation using a forward-viewing endoscope can be particularly challenging and special enteroscope-compatible accessories are required.

Biliary access may also be obtained using a percutaneous approach (PTBD) [185]. Recent advances in the development of LAMSs have made it possible to connect the gastric pouch and excluded stomach to gain access to the papilla using a duodenoscope. This technique is referred to as EUS-directed transgastric ERCP (EDGE).

\subsection{Key question 22: What are the technical and clinical success rates of EDGE?}

The main advantage of EDGE, compared with other modalities for biliary drainage in patients with RYGB, is that the ERCP can be done using a standard duodenoscope. Since its introduction as a therapeutic option, various case series have been published that have described the technical success of EDGE and subsequent ERCP [186]. A recent systematic review evaluated nine case series and eight case reports. In the case series, 169 patients underwent EDGE with a technical success rate of $99 \%$ (168/169) for gastrogastrostomy/jejunogastrostomy creation and $98 \%(166 / 169)$ for subsequent ERCP [184].

\subsection{Key question 23: How does EDGE compare with the alternative procedures?}

\subsubsection{How does EDGE compare with enteroscopy- assisted ERCP?}

\section{RECOMMENDATION}

ESGE suggest that endoscopic ultrasound-directed transgastric ERCP (EDGE) can be offered, in expert centers, to patients with a Roux-en-Y gastric bypass following multidisciplinary decision-making, with the aim of overcoming the invasiveness of laparoscopy-assisted ERCP and the limitations of enteroscopy-assisted ERCP.

Weak recommendation, low quality evidence.

A recent study that compared $L A-E R C P$ with EA-ERCP found both techniques to be similar with regards to technical success, AE rates, and procedure time [187] (Table 11 s). In a retrospective study comparing EA-ERCP, LA-ERCP, and EDGE, EDGE was found to be associated with higher success and lower AE rates [188]. In addition, another retrospective study that compared all three approaches revealed higher technical success for EDGE and LA-ERCP when compared with EA-ERCP (100\% vs. $94 \%$ vs. $75 \%$, respectively; $P=0.02)$, with the latter requiring significantly more procedure time (79 vs. 158 vs. 102 minutes, respectively; $P<0.001$ ) [189].

Similar results were found in a systematic review and metaanalysis of over 1200 patients [190]. This study observed superior technical and clinical success when EDGE was compared with EA-ERCP, although the latter was associated with a lower risk of AEs when compared with both EDGE and LA-ERCP $(8.4 \%$ vs. $21.9 \%$ vs. $17.4 \%$, respectively). It seems reasonable to deduce from these low quality non-randomized studies that EDGE is a safe and effective alternative to surgery. The current evidence also suggests that EDGE is more effective and less time-consuming than EA-ERCP, but that it is associated with more AEs.

Most physicians would, for practical considerations, opt for LA-ERCP in patients where the gallbladder is still in situ as this procedure can be combined with cholecystectomy. EDGE should be considered in patients where cholecystectomy has already been performed or when re-interventions are deemed likely [191]. 


\subsection{Key question 24: What are the most common adverse events with EDGE?}

$A$ recent systematic review reported $A E s$ related to the EDGE procedure in $24 \%$ of cases $(41 / 169)$ [184]. Most of the EDGErelated AEs (31/41) were minor, with 19/41 due to intraprocedural stent migration and eight due to stent maldeployment these AEs could all be managed endoscopically - while postprocedural abdominal pain was reported in the remaining patients. Moderate AEs were observed in nine patients (5.3\%), with bleeding occurring in five and persistent fistula and perforation each in two patients. Only one perforation from stent maldeployment required surgery.

In EDGE procedures, the stent is removed once biliary problems are definitively resolved. In cases of persistence of a large fistula after LAMS removal, weight gain can occur. Given that EDGE placement is often required for a short period, the procedural benefits outweigh the potential likelihood of weight gain [183].

\section{Conclusions}

Advances within therapeutic EUS are evolving rapidly, with technical innovations and emerging clinical applications developing in parallel. As a result, high quality data seem to trail behind the everyday use of these techniques. While these approaches have quickly demonstrated their role in clinical care, various knowledge gaps persist. In many cases, our current unresolved questions are amenable to an RCT, such as the ongoing trials comparing EUS-GE to surgical gastrojejunostomy and EUS-GBD to laparoscopic cholecystectomy. These studies will be invaluable to our understanding of the role of such procedures. However, it should be noted that in other scenarios an RCT may not be feasible, as is the case for EUS-guided PD drainage because of its relative rarity and the lack of a standardized comparator. In scenarios such as this, retrospective comparative data may be our ceiling. For a suggested list of topics for possible future research, please see Appendix $1 \mathrm{~s}$.

\section{Disclaimer}

The legal disclaimer for ESGE guidelines [192] applies to this Guideline.

\section{Acknowledgments}

The authors would like to sincerely thank Professor Marianna Arvanitakis, Hôpital Erasme Brussels, and Professor Takao Itoi, Tokyo Medical University, for their review of this manuscript. The authors are furthermore grateful for the comments provided by: Dr. Mauro Manno (Azienda USL di Modena), Professor Klaus Mergener (University of Washington, Seattle), Professor Riadh Sadik (Sahlgrenska University, Gothenburg), Dr. Leonardo Sosa-Valencia (IHU Strasbourg), Professor Mette Versterhus (University of Bergen), and Dr. Alexander Waldthaler (Karolinska University Hospital, Stockholm).
Competing interests

M. Barthet has received a research grant from Boston Scientific (2015 to present). K.F. Binmoeller has received fees for training and education from Boston Scientific (2015 to present). M. Bronswijk has received consultancy fees from Prion Medical and Taewoong Medical (both 2021). M.A. Khashab receives consultancy fees from BSCl, Medtronic, Olympus, Pentax, GI Supply, and Apollo (all ongoing). A. Larghi has received consultancy fees from Boston Scientific and Pentax Medical, and educational fees from Taewoong Medical; he receives research support from Medtronic. R. Law receives consultancy fees from Medtronic (2020 to present) and Conmed (2021). M. Perez-Miranda receives consultancy fees from Lumendi and Olympus (both 2020 to present) and consultancy and speaker's fees from Boston Scientific (2021). S. van der Merwe has received consultancy fees from Boston Scientific and Cook Endoscopy (both 2012 to present); he was the Boston Chair in Interventional Endoscopy (2018 to 2021) and is the Cook Chair in Portal Hypertension (2021). J.E. van Hooft has received lecture fees from Medtronics (2014, 2015, and 2019), Cook Medical (2019), and Abbivie (2021), and consultancy fees from Boston Scientific (2014 to 2017) and Olympus (2021); her department received research support from Abbott (2014 to 2017) and Cook Medical (2014 to 2019). P.G. Arcidiacono, A. Badaoui, S. Everett, T. Hucl, R. Kunda, S. Lakhtakia, M. Rimbas, and R.L.J. van Wanrooij declare that they have no conflict of interest.

References

[1] Arvanitakis M, Dumonceau JM, Albert J et al. Endoscopic management of acute necrotizing pancreatitis: European Society of Gastrointestinal Endoscopy (ESGE) evidence-based multidisciplinary guidelines. Endoscopy 2018; 50: 524-546

[2] Guyatt G, Oxman AD, Akl EA et al. GRADE guidelines: 1. Introduction-GRADE evidence profiles and summary of findings tables. J Clin Epidemiol 2011; 64: 383-394

[3] Dumonceau JM, Tringali A, Blero D et al. Biliary stenting: indications, choice of stents and results: European Society of Gastrointestinal Endoscopy (ESGE) clinical guideline. Endoscopy 2012; 44: 277-298

[4] Kahaleh M, Artifon EL, Perez-Miranda M et al. Endoscopic ultrasonography guided biliary drainage: summary of consortium meeting, May 7th, 2011, Chicago. World J Gastroenterol 2013; 19: 13721379

[5] Mukai S, Itoi T, Baron TH et al. Indications and techniques of biliary drainage for acute cholangitis in updated Tokyo Guidelines 2018. J Hepatobiliary Pancreat Sci 2017; 24: 537-549

[6] Teoh AYB, Dhir V, Kida M et al. Consensus guidelines on the optimal management in interventional EUS procedures: results from the Asian EUS group RAND/UCLA expert panel. Gut 2018; 67: 12091228

[7] Anderloni A, Fugazza A, Pellegatta G et al. Endoscopic choledochoduodenostomy by lumen-apposing metal stent in jaundice recurrence after transpapillary metal stent placement. Endoscopy 2019; 51: E239-E240

[8] Bang JY, Navaneethan U, Hasan M et al. Stent placement by EUS or ERCP for primary biliary decompression in pancreatic cancer: a randomized trial (with videos). Gastrointest Endosc 2018; 88: 9-17

[9] Chin JY, Seleq S, Weilert F. Safety and outcomes of endoscopic ultrasound-guided drainage for malignant biliary obstruction using cautery-enabled lumen-apposing metal stent. Endosc Int Open 2020; 8: E1633-E1638

[10] Cho DH, Lee SS, Oh D et al. Long-term outcomes of a newly developed hybrid metal stent for EUS-guided biliary drainage (with videos). Gastrointest Endosc 2017; 85: 1067-1075 
[11] de Benito Sanz M, Najera-Munoz R, de la Serna-Higuera C et al. Lumen apposing metal stents versus tubular self-expandable metal stents for endoscopic ultrasound-guided choledochoduodenostomy in malignant biliary obstruction. Surg Endosc 2021; 35: 6754-6762

[12] Dhir V, Itoi T, Khashab MA et al. Multicenter comparative evaluation of endoscopic placement of expandable metal stents for malignant distal common bile duct obstruction by ERCP or EUS-guided approach. Gastrointest Endosc 2015; 81: 913-923

[13] El Chafic AH, Shah JN, Hamerski C et al. EUS-guided choledochoduodenostomy for distal malignant biliary obstruction using electrocautery-enhanced lumen-apposing metal stents: First US, multicenter experience. Dig Dis Sci 2019; 64: 3321-3327

[14] Garcia-Sumalla A, Loras C, Guarner-Argente $C$ et al. Is a coaxial plastic stent within a lumen-apposing metal stent useful for the management of distal malignant biliary obstruction? Surg Endosc 2021; 35: $4873-4881$

[15] Honjo M, Itoi T, Tsuchiya T et al. Safety and efficacy of ultra-tapered mechanical dilator for EUS-guided hepaticogastrostomy and pancreatic duct drainage compared with electrocautery dilator (with video). Endosc Ultrasound 2018; 7: 376-382

[16] Jacques J, Privat J, Pinard F et al. EUS-guided choledochoduodenostomy by use of electrocautery-enhanced lumen-apposing metal stents: a French multicenter study after implementation of the technique (with video). Gastrointest Endosc 2020; 92: 134-141

[17] Jacques J, Privat J, Pinard F et al. Endoscopic ultrasound-guided choledochoduodenostomy with electrocautery-enhanced lumenapposing stents: a retrospective analysis. Endoscopy 2019; 51: 540547

[18] Kawakubo $\mathrm{K}$, Isayama $\mathrm{H}$, Kato $\mathrm{H}$ et al. Multicenter retrospective study of endoscopic ultrasound-guided biliary drainage for malignant biliary obstruction in Japan. J Hepatobiliary Pancreat Sci 2014; 21: $328-334$

[19] Khashab MA, Messallam AA, Penas I et al. International multicenter comparative trial of transluminal EUS-guided biliary drainage via hepatogastrostomy vs. choledochoduodenostomy approaches. Endosc Int Open 2016; 4: E175-E181

[20] Khashab MA, van der Merwe S, Kunda R et al. Prospective international multicenter study on endoscopic ultrasound-guided biliary drainage for patients with malignant distal biliary obstruction after failed endoscopic retrograde cholangiopancreatography. Endosc Int Open 2016; 4: E487-E496

[21] Kunda R, Perez-Miranda M, Will U et al. EUS-guided choledochoduodenostomy for malignant distal biliary obstruction using a lumen-apposing fully covered metal stent after failed ERCP. Surg Endosc 2016; 30: 5002-5008

[22] Kuraoka N, Hara K, Okuno N et al. Outcomes of EUS-guided choledochoduodenostomy as primary drainage for distal biliary obstruction with covered self-expandable metallic stents. Endosc Int Open 2020; 8: E861-E868

[23] Minaga K, Takenaka M, Kitano M et al. Rescue EUS-guided intrahepatic biliary drainage for malignant hilar biliary stricture after failed transpapillary re-intervention. Surg Endosc 2017; 31: 4764-4772

[24] Miyano A, Ogura T, Yamamoto K et al. Clinical impact of the intrascope channel stent release technique in preventing stent migration during EUS-guided hepaticogastrostomy. J Gastrointest Surg 2018; 22: $1312-1318$

[25] Nakai $\mathrm{Y}$, Isayama $\mathrm{H}$, Kawakami $\mathrm{H}$ et al. Prospective multicenter study of primary EUS-guided choledochoduodenostomy using a covered metal stent. Endosc Ultrasound 2019; 8: 111-117

[26] Nakai $Y$, Isayama $\mathrm{H}$, Yamamoto $\mathrm{N}$ et al. Safety and effectiveness of a long, partially covered metal stent for endoscopic ultrasound-guided hepaticogastrostomy in patients with malignant biliary obstruction. Endoscopy 2016; 48: 1125-1128
[27] Ogura T, Kitano M, Takenaka M et al. Multicenter prospective evaluation study of endoscopic ultrasound-guided hepaticogastrostomy combined with antegrade stenting (with video). Dig Endosc 2018; 30: $252-259$

[28] Oh D, Park DH, Song T] et al. Optimal biliary access point and learning curve for endoscopic ultrasound-guided hepaticogastrostomy with transmural stenting. Therap Adv Gastroenterol 2017; 10: 4253

[29] Paik WH, Lee TH, Park DH et al. EUS-guided biliary drainage versus ERCP for the primary palliation of malignant biliary obstruction: a multicenter randomized clinical trial. Am J Gastroenterol 2018; 113: 987-997

[30] Poincloux L, Rouquette O, Buc E et al. Endoscopic ultrasound-guided biliary drainage after failed ERCP: cumulative experience of 101 procedures at a single center. Endoscopy 2015; 47: 794-801

[31] Rai P, Lokesh CR, Goel A et al. Endoscopic ultrasound-guided choledochoduodenostomy using partially-covered self-expandable metal stent in patients with malignant distal biliary obstruction and unsuccessful ERCP. Endosc Int Open 2018; 6: E67-E72

[32] Sportes A, Camus M, Greget M et al. Endoscopic ultrasound-guided hepaticogastrostomy versus percutaneous transhepatic drainage for malignant biliary obstruction after failed endoscopic retrograde cholangiopancreatography: a retrospective expertise-based study from two centers. Therap Adv Gastroenterol 2017; 10: 483-493

[33] Vanella G, Bronswijk M, Maleux G et al. EUS-guided intrahepatic biliary drainage: a large retrospective series and subgroup comparison between percutaneous drainage in hilar stenoses or postsurgical anatomy. Endosc Int Open 2020; 8: E1782-E1794

[34] Vila J], Perez-Miranda M, Vazquez-Sequeiros E et al. Initial experience with EUS-guided cholangiopancreatography for biliary and pancreatic duct drainage: a Spanish national survey. Gastrointest Endosc 2012; 76: 1133-1141

[35] Hedjoudje A, Sportes A, Grabar S et al. Outcomes of endoscopic ultrasound-guided biliary drainage: A systematic review and metaanalysis. United European Gastroenterol J 2019; 7: 60-68

[36] Khan MA, Akbar A, Baron TH et al. Endoscopic ultrasound-guided biliary drainage: a systematic review and meta-analysis. Dig Dis Sci 2016; 61: 684-703

[37] Uemura RS, Khan MA, Otoch JP et al. EUS-guided choledochoduodenostomy versus hepaticogastrostomy: a systematic review and meta-analysis. J Clin Gastroenterol 2018; 52: 123-130

[38] Amano M, Ogura T, Onda S et al. Prospective clinical study of endoscopic ultrasound-guided biliary drainage using novel balloon catheter (with video). J Gastroenterol Hepatol 2017; 32: 716-720

[39] Artifon EL, Marson FP, Gaidhane M et al. Hepaticogastrostomy or choledochoduodenostomy for distal malignant biliary obstruction after failed ERCP: is there any difference? Gastrointest Endosc 2015; 81: 950-959

[40] Guo J, Sun S, Liu X et al. Endoscopic ultrasound-guided biliary drainage using a fully covered metallic stent after failed endoscopic retrograde cholangiopancreatography. Gastroenterol Res Pract 2016; 2016: 9469472

[41] Kim TH, Kim SH, Oh HJ et al. Endoscopic ultrasound-guided biliary drainage with placement of a fully covered metal stent for malignant biliary obstruction. World J Gastroenterol 2012; 18: 2526-2532

[42] Minaga K, Ogura T, Shiomi H et al. Comparison of the efficacy and safety of endoscopic ultrasound-guided choledochoduodenostomy and hepaticogastrostomy for malignant distal biliary obstruction: Multicenter, randomized, clinical trial. Dig Endosc 2019; 31: 575582

[43] Ogura T, Chiba Y, Masuda D et al. Comparison of the clinical impact of endoscopic ultrasound-guided choledochoduodenostomy and hepaticogastrostomy for bile duct obstruction with duodenal obstruction. Endoscopy 2016; 48: 156-163 
[44] Park DH, Jang JW, Lee SS et al. EUS-guided biliary drainage with transluminal stenting after failed ERCP: predictors of adverse events and long-term results. Gastrointest Endosc 2011; 74: 1276-1284

[45] Park DH, Lee TH, Paik WH et al. Feasibility and safety of a novel dedicated device for one-step EUS-guided biliary drainage: A randomized trial. J Gastroenterol Hepatol 2015; 30: 1461-1466

[46] Prachayakul V, Aswakul P. A novel technique for endoscopic ultrasound-guided biliary drainage. World J Gastroenterol 2013; 19: 4758-4763

[47] Dhir V, Bhandari S, Bapat M et al. Comparison of transhepatic and extrahepatic routes for EUS-guided rendezvous procedure for distal CBD obstruction. United European Gastroenterol J 2013; 1: 103-108

[48] Dhir V, Bhandari S, Bapat M et al. Comparison of EUS-guided rendezvous and precut papillotomy techniques for biliary access (with videos). Gastrointest Endosc 2012; 75: 354-359

[49] Iwashita T, Lee JG, Shinoura $S$ et al. Endoscopic ultrasound-guided rendezvous for biliary access after failed cannulation. Endoscopy 2012; 44: 60-65

[50] Iwashita T, Yasuda I, Mukai T et al. EUS-guided rendezvous for difficult biliary cannulation using a standardized algorithm: a multicenter prospective pilot study (with videos). Gastrointest Endosc 2016; 83: $394-400$

[51] Kahaleh M, Hernandez A], Tokar J et al. Interventional EUS-guided cholangiography: evaluation of a technique in evolution. Gastrointest Endosc 2006; 64: 52-59

[52] Shah JN, Marson F, Weilert F et al. Single-operator, single-session EUS-guided anterograde cholangiopancreatography in failed ERCP or inaccessible papilla. Gastrointest Endosc 2012; 75: 56-64

[53] Wang K, Zhu J, Xing L et al. Assessment of efficacy and safety of EUSguided biliary drainage: a systematic review. Gastrointest Endosc 2016; 83: 1218-1227

[54] Iwashita T, Yasuda I, Mukai T et al. Endoscopic ultrasound-guided antegrade biliary stenting for unresectable malignant biliary obstruction in patients with surgically altered anatomy: Single-center prospective pilot study. Dig Endosc 2017; 29: 362-368

[55] Imai H, Kitano M, Omoto S et al. EUS-guided gallbladder drainage for rescue treatment of malignant distal biliary obstruction after unsuccessful ERCP. Gastrointest Endosc 2016; 84: 147-151

[56] Issa D, Irani S, Law R et al. Endoscopic ultrasound-guided gallbladder drainage as a rescue therapy for unresectable malignant biliary obstruction: a multicenter experience. Endoscopy 2021; 53: 827-831

[57] Martinez B, Martinez J, Casellas JA et al. Endoscopic ultrasoundguided rendezvous in benign biliary or pancreatic disorders with a 22-gauge needle and a 0.018-inch guidewire. Endosc Int Open 2019; 7: E1038-E1043

[58] Ogura T, Takenaka M, Shiomi H et al. Long-term outcomes of EUSguided transluminal stent deployment for benign biliary disease: Multicenter clinical experience (with videos). Endosc Ultrasound 2019; 8: 398-403

[59] Pizzicannella M, Caillol F, Pesenti C et al. EUS-guided biliary drainage for the management of benign biliary strictures in patients with altered anatomy: A single-center experience. Endosc Ultrasound 2020; 9: 45-52

[60] Shiomi H, Yamao K, Hoki N et al. Endoscopic ultrasound-guided rendezvous technique for failed biliary cannulation in benign and resectable malignant biliary disorders. Dig Dis Sci 2018; 63: 787796

[61] Hosmer A, Abdelfatah MM, Law R et al. Endoscopic ultrasoundguided hepaticogastrostomy and antegrade clearance of biliary lithiasis in patients with surgically-altered anatomy. Endosc Int Open 2018; 6: E127-E130
[62] Mukai S, Itoi T, Sofuni A et al. EUS-guided antegrade intervention for benign biliary diseases in patients with surgically altered anatomy (with videos). Gastrointest Endosc 2019; 89: 399-407

[63] Bill JG, Ryou M, Hathorn KE et al. Endoscopic ultrasound-guided biliary drainage in benign biliary pathology with normal foregut anatomy: a multicenter study. Surg Endosc 2021: doi:10.1007/s00464021-08418-w

[64] Nakai $\mathrm{Y}$, Kogure $\mathrm{H}$, Isayama $\mathrm{H}$ et al. Endoscopic ultrasound-guided biliary drainage for benign biliary diseases. Clin Endosc 2019; 52: 212-219

[65] Khashab MA, Valeshabad AK, Modayil R et al. EUS-guided biliary drainage by using a standardized approach for malignant biliary obstruction: rendezvous versus direct transluminal techniques (with videos). Gastrointest Endosc 2013; 78: 734-741

[66] Kongkam P, Tasneem AA, Rerknimitr R. Combination of endoscopic retrograde cholangiopancreatography and endoscopic ultrasonography-guided biliary drainage in malignant hilar biliary obstruction. Dig Endosc 2019; 31: (Suppl. 01): 50-54

[67] Moole H, Dharmapuri S, Duvvuri A et al. Endoscopic versus percutaneous biliary drainage in palliation of advanced malignant hilar obstruction: a meta-analysis and systematic review. Can J Gastroenterol Hepatol 2016; 2016: 4726078

[68] Ma KW, So H, Cho DH et al. Durability and outcome of endoscopic ultrasound-guided hepaticoduodenostomy using a fully covered metal stent for segregated right intrahepatic duct dilatation. J Gastroenterol Hepatol 2020; 35: 1753-1760

[69] Park S], Choi JH, Park DH et al. Expanding indication: EUS-guided hepaticoduodenostomy for isolated right intrahepatic duct obstruction (with video). Gastrointest Endosc 2013; 78: 374-380

[70] Sundaram S, Dhir V. EUS-guided biliary drainage for malignant hilar biliary obstruction: A concise review. Endosc Ultrasound 2021; 10: 154-160

[71] Nennstiel S, Weber A, Frick G et al. Drainage-related complications in percutaneous transhepatic biliary drainage: an analysis over 10 years. J Clin Gastroenterol 2015; 49: 764-770

[72] Artifon EL, Aparicio D, Paione JB et al. Biliary drainage in patients with unresectable, malignant obstruction where ERCP fails: endoscopic ultrasonography-guided choledochoduodenostomy versus percutaneous drainage. J Clin Gastroenterol 2012; 46: 768-774

[73] Bapaye A, Dubale N, Aher A. Comparison of endosonography-guided vs. percutaneous biliary stenting when papilla is inaccessible for ERCP. United European Gastroenterol J 2013; 1: 285-293

[74] Khashab MA, Valeshabad AK, Afghani E et al. A comparative evaluation of EUS-guided biliary drainage and percutaneous drainage in patients with distal malignant biliary obstruction and failed ERCP. Dig Dis Sci 2015; 60: 557-565

[75] Sharaiha RZ, Kumta NA, Desai AP et al. Endoscopic ultrasoundguided biliary drainage versus percutaneous transhepatic biliary drainage: predictors of successful outcome in patients who fail endoscopic retrograde cholangiopancreatography. Surg Endosc 2016; 30: 5500-5505

[76] Lee TH, Choi JH, Park DH et al. Similar efficacies of endoscopic ultrasound-guided transmural and percutaneous drainage for malignant distal biliary obstruction. Clin Gastroenterol Hepatol 2016; 14: 1011-1019 e3

[77] Sharaiha RZ, Khan MA, Kamal F et al. Efficacy and safety of EUSguided biliary drainage in comparison with percutaneous biliary drainage when ERCP fails: a systematic review and meta-analysis. Gastrointest Endosc 2017; 85: 904-914

[78] Dumonceau JM, Tringali A, Papanikolaou IS et al. Endoscopic biliary stenting: indications, choice of stents, and results: European Society of Gastrointestinal Endoscopy (ESGE) Clinical Guideline - Updated October 2017. Endoscopy 2018; 50: 910-930 
[79] Coelen RJS, Roos E, Wiggers JK et al. Endoscopic versus percutaneous biliary drainage in patients with resectable perihilar cholangiocarcinoma: a multicentre, randomised controlled trial. Lancet Gastroenterol Hepatol 2018; 3: 681-690

[80] Moryoussef F, Sportes A, Leblanc S et al. Is EUS-guided drainage a suitable alternative technique in case of proximal biliary obstruction? Therap Adv Gastroenterol 2017; 10: 537-544

[81] Kongkam P, Orprayoon T, Boonmee C et al. ERCP plus endoscopic ultrasound-guided biliary drainage versus percutaneous transhepatic biliary drainage for malignant hilar biliary obstruction: a multicenter observational open-label study. Endoscopy 2021; 53: 55-62

[82] Park JK, Woo YS, Noh DH et al. Efficacy of EUS-guided and ERCPguided biliary drainage for malignant biliary obstruction: prospective randomized controlled study. Gastrointest Endosc 2018; 88: $277-282$

[83] Gaujoux S, Jacques ], Bourdariat R et al. Pancreaticoduodenectomy following endoscopic ultrasound-guided choledochoduodenostomy with electrocautery-enhanced lumen-apposing stents an ACHBT SFED study. HPB (Oxford) 2021; 23: 154-160

[84] Colan-Hernandez J, Aldana A, Concepcion M et al. Optimal timing for a second ERCP after failure of initial biliary cannulation following precut sphincterotomy: an analysis of experience at two tertiary centers. Surg Endosc 2017; 31: 3711-3717

[85] Swan MP, Bourke MJ, Williams SJ et al. Failed biliary cannulation: clinical and technical outcomes after tertiary referral endoscopic retrograde cholangiopancreatography. World J Gastroenterol 2011; 17: 4993-4998

[86] Gupta K, Perez-Miranda M, Kahaleh M et al. Endoscopic ultrasoundassisted bile duct access and drainage: multicenter, long-term analysis of approach, outcomes, and complications of a technique in evolution. J Clin Gastroenterol 2014; 48: 80-87

[87] Skinner M, Popa D, Neumann H et al. ERCP with the overtubeassisted enteroscopy technique: a systematic review. Endoscopy 2014; 46: 560-572

[88] Minaga K, Takenaka M, Ogura T et al. Endoscopic ultrasound-guided biliary drainage for malignant biliary obstruction with surgically altered anatomy: a multicenter prospective registration study. Therap Adv Gastroenterol 2020; 13: 1756284820930964

[89] Iwashita T, Yasuda I, Doi S et al. Endoscopic ultrasound-guided antegrade treatments for biliary disorders in patients with surgically altered anatomy. Dig Dis Sci 2013; 58: 2417-2422

[90] James TW, Fan YC, Baron TH. EUS-guided hepaticoenterostomy as a portal to allow definitive antegrade treatment of benign biliary diseases in patients with surgically altered anatomy. Gastrointest Endosc 2018; 88: 547-554

[91] Mukai S, Tsuchiya T, Itoi T. Interventional endoscopic ultrasonography for benign biliary diseases in patients with surgically altered anatomy. Curr Opin Gastroenterol 2019; 35: 408-415

[92] Cotton PB, Eisen GM, Aabakken L et al. A lexicon for endoscopic adverse events: report of an ASGE workshop. Gastrointest Endosc 2010; 71: 446-454

[93] Nakai Y, Sato T, Hakuta R et al. Long-term outcomes of a long, partially covered metal stent for EUS-guided hepaticogastrostomy in patients with malignant biliary obstruction (with video). Gastrointest Endosc 2020; 92: 623-631 e1

[94] Mohan BP, Shakhatreh M, Garg R et al. Efficacy and safety of endoscopic ultrasound-guided choledochoduodenostomy: a systematic review and meta-analysis. J Clin Gastroenterol 2019; 53: 243-250

[95] Han SY, Kim SO, So $\mathrm{H}$ et al. EUS-guided biliary drainage versus ERCP for first-line palliation of malignant distal biliary obstruction: A systematic review and meta-analysis. Sci Rep 2019; 9: 16551

[96] Kanno Y, Koshita S, Ogawa T et al. EUS-guided biliary drainage for unresectable malignant biliary obstruction: 10-year experience of 99 cases at a single center. J Gastrointest Cancer 2019; 50: 469-477
[97] Mangas-Sanjuan C, Bozhychko M, Martinez ] et al. Endoscopic management of accidental portal vein puncture during endoscopic ultrasound-guided choledochoduodenostomy. Endoscopy 2020; 52: E47-E48

[98] Jin Z, Wei Y, Lin $\mathrm{H}$ et al. Endoscopic ultrasound-guided versus endoscopic retrograde cholangiopancreatography-guided biliary drainage for primary treatment of distal malignant biliary obstruction: A systematic review and meta-analysis. Dig Endosc 2020; 32: 16-26

[99] Okuno N, Hara K, Mizuno N et al. Endoscopic ultrasound-guided rendezvous technique after failed endoscopic retrograde cholangiopancreatography: which approach route is the best? Intern Med 2017; 56: 3135-3143

[100] Godat S, Bories E, Caillol F et al. Efficacy and safety in case of technical success of endoscopic ultrasound-guided transhepatic antegrade biliary drainage: A report of a monocentric study. Endosc Ultrasound 2017; 6: 181-186

[101] Ali UA, Pahlplatz JM, Nealon WH et al. Endoscopic or surgical intervention for painful obstructive chronic pancreatitis. Cochrane Database Syst Rev 2015: CD007884

[102] Brauer BC, Chen YK, Fukami N et al. Single-operator EUS-guided cholangiopancreatography for difficult pancreaticobiliary access (with video). Gastrointest Endosc 2009; 70: 471-479

[103] Chen YI, Levy M], Moreels TG et al. An international multicenter study comparing EUS-guided pancreatic duct drainage with enteroscopy-assisted endoscopic retrograde pancreatography after Whipple surgery. Gastrointest Endosc 2017; 85: 170-177

[104] Krafft MR, Nasr JY. Anterograde endoscopic ultrasound-guided pancreatic duct drainage: a technical review. Dig Dis Sci 2019; 64: $1770-1781$

[105] Itoi T, Kasuya K, Sofuni A et al. Endoscopic ultrasonography-guided pancreatic duct access: techniques and literature review of pancreatography, transmural drainage and rendezvous techniques. Dig Endosc 2013; 25: 241-252

[106] Fujii LL, Topazian MD, Abu Dayyeh BK et al. EUS-guided pancreatic duct intervention: outcomes of a single tertiary-care referral center experience. Gastrointest Endosc 2013; 78: 854-864 e1

[107] Shimamura Y, Mosko J, Teshima C et al. Endoscopic ultrasoundguided pancreatic duct intervention. Clin Endosc 2017; 50: 112-116

[108] Siddiqui UD, Levy M]. EUS-guided transluminal interventions. Gastroenterology 2018; 154: 1911-1924

[109] Basiliya K, Veldhuijzen G, Gerges C et al. Endoscopic retrograde pancreatography-guided versus endoscopic ultrasound-guided technique for pancreatic duct cannulation in patients with pancreaticojejunostomy stenosis: a systematic literature review. Endoscopy 2021; 53: 266-276

[110] Francois E, Kahaleh M, Giovannini M et al. EUS-guided pancreaticogastrostomy. Gastrointest Endosc 2002; 56: 128-133

[111] Kahaleh M, Hernandez AJ, Tokar J et al. EUS-guided pancreaticogastrostomy: analysis of its efficacy to drain inaccessible pancreatic ducts. Gastrointest Endosc 2007; 65: 224-230

[112] Oh D, Park DH, Cho MK et al. Feasibility and safety of a fully covered self-expandable metal stent with antimigration properties for EUSguided pancreatic duct drainage: early and midterm outcomes (with video). Gastrointest Endosc 2016; 83: 366-373 e2

[113] Khan Z, Hayat U, Moraveji S et al. EUS-guided pancreatic ductal intervention: A comprehensive literature review. Endosc Ultrasound 2021; 10: 98-102

[114] Tyberg A, Sharaiha RZ, Kedia P et al. EUS-guided pancreatic drainage for pancreatic strictures after failed ERCP: a multicenter international collaborative study. Gastrointest Endosc 2017; 85: 164-169 
[115] Tessier G, Bories E, Arvanitakis M et al. EUS-guided pancreatogastrostomy and pancreatobulbostomy for the treatment of pain in patients with pancreatic ductal dilatation inaccessible for transpapillary endoscopic therapy. Gastrointest Endosc 2007; 65: 233-241

[116] Garcia-Alonso FJ, Penas-Herrero I, Sanchez-Ocana R et al. The role of endoscopic ultrasound guidance for biliary and pancreatic duct access and drainage to overcome the limitations of ERCP: a retrospective evaluation. Endoscopy 2021; 53: 691-699

[117] Chahal P, Baron TH, Topazian MD et al. Endoscopic retrograde cholangiopancreatography in post-Whipple patients. Endoscopy 2006; 38: 1241-1245

[118] Krafft MR, Croglio MP, James TW et al. Endoscopic endgame for obstructive pancreatopathy: outcomes of anterograde EUS-guided pancreatic duct drainage. A dual-center study. Gastrointest Endosc 2020; 92: 1055-1066

[119] Krishnamoorthi R, Ross A. EUS-directed pancreatic duct drainage: Mainstream miracle or proceed with caution? Gastrointest Endosc 2020; 92: 1067-1069

[120] Widmer ], Sharaiha RZ, Kahaleh M. Endoscopic ultrasonographyguided drainage of the pancreatic duct. Gastrointest Endosc Clin N Am 2013; 23: 847-861

[121] Mori Y, Itoi T, Baron TH et al. Tokyo Guidelines 2018: management strategies for gallbladder drainage in patients with acute cholecystitis (with videos). J Hepatobiliary Pancreat Sci 2018; 25: 87-95

[122] Teoh AYB. Outcomes and limitations in EUS-guided gallbladder drainage. Endosc Ultrasound 2019; 8: S40-S43

[123] Anderloni A, Buda A, Vieceli F et al. Endoscopic ultrasound-guided transmural stenting for gallbladder drainage in high-risk patients with acute cholecystitis: a systematic review and pooled analysis. Surg Endosc 2016; 30: 5200-5208

[124] Park SW, Lee SS. Current status of endoscopic management of cholecystitis. Dig Endosc 2021: doi:10.1111/den.14083

[125] Walter D, Teoh AY, Itoi T et al. EUS-guided gall bladder drainage with a lumen-apposing metal stent: a prospective long-term evaluation. Gut 2016; 65: 6-8

[126] Choi JH, Lee SS, Park DH et al. Long-term outcomes after endoscopic ultrasonography-guided gallbladder drainage for acute cholecystitis. Endoscopy 2014; 46: 656-661

[127] Kalva NR, Vanar V, Forcione D et al. Efficacy and safety of lumen apposing self-expandable metal stents for EUS guided cholecystostomy: a meta-analysis and systematic review. Can J Gastroenterol Hepatol 2018; 2018: 7070961

[128] Kamata K, Takenaka M, Kitano M et al. Endoscopic ultrasound-guided gallbladder drainage for acute cholecystitis: Long-term outcomes after removal of a self-expandable metal stent. World J Gastroenterol 2017; 23: 661-667

[129] James TW, Baron TH. EUS-guided gallbladder drainage: A review of current practices and procedures. Endosc Ultrasound 2019; 8: S28S34

[130] Perez-Miranda M. Technical considerations in EUS-guided gallbladder drainage. Endosc Ultrasound 2018; 7: 79-82

[131] Chang JI, Dong E, Kwok KK. Endoscopic ultrasound-guided transmural gallbladder drainage in malignant obstruction using a novel lumen-apposing stent: a case series (with video). Endosc Int Open 2019; 7: E655-E661

[132] Jang JW, Lee SS, Song T] et al. Endoscopic ultrasound-guided transmural and percutaneous transhepatic gallbladder drainage are comparable for acute cholecystitis. Gastroenterology 2012; 142: 805-811

[133] Teoh AYB, Kitano M, Itoi T et al. Endosonography-guided gallbladder drainage versus percutaneous cholecystostomy in very high-risk surgical patients with acute cholecystitis: an international rando- mised multicentre controlled superiority trial (DRAC 1). Gut 2020; 69: 1085-1091

[134] Luk SW, Irani S, Krishnamoorthi R et al. Endoscopic ultrasoundguided gallbladder drainage versus percutaneous cholecystostomy for high risk surgical patients with acute cholecystitis: a systematic review and meta-analysis. Endoscopy 2019; 51: 722-732

[135] Saumoy M, Novikov A, Kahaleh M. Long-term outcomes after EUSguided gallbladder drainage. Endosc Ultrasound 2018; 7: 97-101

[136] Ahmed O, Rogers AC, Bolger JC et al. Meta-analysis of outcomes of endoscopic ultrasound-guided gallbladder drainage versus percutaneous cholecystostomy for the management of acute cholecystitis. Surg Endosc 2018; 32: 1627-1635

[137] Siddiqui A, Kunda R, Tyberg A et al. Three-way comparative study of endoscopic ultrasound-guided transmural gallbladder drainage using lumen-apposing metal stents versus endoscopic transpapillary drainage versus percutaneous cholecystostomy for gallbladder drainage in high-risk surgical patients with acute cholecystitis: clinical outcomes and success in an international, multicenter study. Surg Endosc 2019; 33: 1260-1270

[138] Krishnamoorthi R, Jayaraj M, Thoguluva Chandrasekar V et al. EUSguided versus endoscopic transpapillary gallbladder drainage in high-risk surgical patients with acute cholecystitis: a systematic review and meta-analysis. Surg Endosc 2020; 34: 1904-1913

[139] Bronswijk M, van Malenstein H, Laleman W et al. EUS-guided gastroenterostomy: Less is more! The wireless EUS-guided gastroenterostomy simplified technique VideoGIE 2020; 5: 442

[140] Bronswijk M, Vanella G, van Malenstein H et al. Laparoscopic versus EUS-guided gastroenterostomy for gastric outlet obstruction: an international multicenter propensity score-matched comparison (with video). Gastrointest Endosc 2021; 94: 526-536.e2

[141] Itoi T, Baron TH, Khashab MA et al. Technical review of endoscopic ultrasonography-guided gastroenterostomy in 2017. Dig Endosc 2017; 29: 495-502

[142] Marrache MK, Itani MI, Farha J et al. Endoscopic gastrointestinal anastomosis: a review of established techniques. Gastrointest Endosc 2021; 93: 34-46

[143] Tonozuka R, Tsuchiya T, Mukai S et al. Endoscopic ultrasonographyguided gastroenterostomy techniques for treatment of malignant gastric outlet obstruction. Clin Endosc 2020; 53: 510-518

[144] Antonelli G, Kovacevic B, Karstensen JG et al. Endoscopic ultrasoundguided gastro-enteric anastomosis: A systematic review and metaanalysis. Dig Liver Dis 2020; 52: 1294-1301

[145] Chen YI, Kunda R, Storm AC et al. EUS-guided gastroenterostomy: a multicenter study comparing the direct and balloon-assisted techniques. Gastrointest Endosc 2018; 87: 1215-1221

[146] Khashab MA, Bukhari M, Baron TH et al. International multicenter comparative trial of endoscopic ultrasonography-guided gastroenterostomy versus surgical gastrojejunostomy for the treatment of malignant gastric outlet obstruction. Endosc Int Open 2017; 5: E275-E281

[147] Perez-Miranda M, Tyberg A, Poletto D et al. EUS-guided gastrojejunostomy versus laparoscopic gastrojejunostomy: an international collaborative study. J Clin Gastroenterol 2017; 51: 896-899

[148] James TW, Greenberg S, Grimm IS et al. EUS-guided gastroenteric anastomosis as a bridge to definitive treatment in benign gastric outlet obstruction. Gastrointest Endosc 2020; 91: 537-542

[149] Chen YI, Itoi T, Baron TH et al. EUS-guided gastroenterostomy is comparable to enteral stenting with fewer re-interventions in malignant gastric outlet obstruction. Surg Endosc 2017; 31: 29462952

[150] Tringali A, Giannetti A, Adler DG. Endoscopic management of gastric outlet obstruction disease. Ann Gastroenterol 2019; 32: 330-337 
[151] Kiriukova M, de la Iglesia Garcia D, Panic N et al. Pancreatic cancer malnutrition and pancreatic exocrine insufficiency in the course of chemotherapy in unresectable pancreatic cancer. Front Med (Lausanne) 2020; 7: 495

[152] Fiori E, Lamazza A, Volpino P et al. Palliative management of malignant antro-pyloric strictures. Gastroenterostomy vs. endoscopic stenting. A randomized prospective trial. Anticancer Res 2004; 24: 269-271

[153] Jeurnink SM, Steyerberg EW, van Hooft JE et al. Surgical gastrojejunostomy or endoscopic stent placement for the palliation of malignant gastric outlet obstruction (SUSTENT study): a multicenter randomized trial. Gastrointest Endosc 2010; 71: 490-499

[154] Mehta S, Hindmarsh A, Cheong E et al. Prospective randomized trial of laparoscopic gastrojejunostomy versus duodenal stenting for malignant gastric outflow obstruction. Surg Endosc 2006; 20: 239242

[155] Minata MK, Bernardo WM, Rocha RS et al. Stents and surgical interventions in the palliation of gastric outlet obstruction: a systematic review. Endosc Int Open 2016; 4: E1158-E1170

[156] ASGE Standards of Practice Committee, Jue TL, Storm AC et al. ASGE guideline on the role of endoscopy in the management of benign and malignant gastroduodenal obstruction. Gastrointest Endosc 2021; 93: 309-322 e4

[157] Chen YI, James TW, Agarwal A et al. EUS-guided gastroenterostomy in management of benign gastric outlet obstruction. Endosc Int Open 2018; 6: E363-E368

[158] Hu J, Wang G, Zhang K et al. Retrieval anchor-assisted endoscopic ultrasound-guided gastroenterostomy for gastric outlet obstruction. Scand J Gastroenterol 2020; 55: 865-868

[159] Jovani M, Ichkhanian Y, Parsa $N$ et al. Assessment of the learning curve for EUS-guided gastroenterostomy for a single operator. Gastrointest Endosc 2021; 93: 1088-1093

[160] Kastelijn JB, van der Voort V, Bijlsma A et al. Early lumen-apposing metal stent dysfunction complicating endoscopic ultrasound-guided gastroenterostomy: a report of two cases. Clin Endosc 2021; 54: 603-607

[161] Kerdsirichairat T, Irani S, Yang J et al. Durability and long-term outcomes of direct EUS-guided gastroenterostomy using lumen-apposing metal stents for gastric outlet obstruction. Endosc Int Open 2019; 7: E144-E150

[162] Khashab MA. EUS-guided gastroenterostomy vs duodenal stenting for the palliation of malignant gastric outlet obstruction. Gastroenterol Hepatol (NY) 2019; 15: 323-325

[163] Kouanda A, Binmoeller K, Hamerski C et al. Endoscopic ultrasoundguided gastroenterostomy versus open surgical gastrojejunostomy: clinical outcomes and cost effectiveness analysis. Surg Endosc 2021; 35: 7058-7067

[164] Tyberg A, Perez-Miranda M, Sanchez-Ocana R et al. Endoscopic ultrasound-guided gastrojejunostomy with a lumen-apposing metal stent: a multicenter, international experience. Endosc Int Open 2016; 4: E276-E281

[165] Xu G, Shen Y, Lv Y et al. Safety and efficacy of endoscopic ultrasound-guided gastroenterostomy using double balloon occlusion methods: a clinical retrospective study in 36 patients with malignant gastric outlet obstruction. Endosc Int Open 2020; 8: E1690-E1697

[166] Fan W, Tan S, Wang J et al. Clinical outcomes of endoscopic ultrasound-guided gastroenterostomy for gastric outlet obstruction: a systematic review and meta-analysis. Minim Invasive Ther Allied Technol 2020: doi:10.1080/13645706.2020.1792500

[167] Iqbal U, Khara HS, Hu Y et al. EUS-guided gastroenterostomy for the management of gastric outlet obstruction: A systematic review and meta-analysis. Endosc Ultrasound 2020; 9: 16-23
[168] McCarty TR, Garg R, Thompson CC et al. Efficacy and safety of EUSguided gastroenterostomy for benign and malignant gastric outlet obstruction: a systematic review and meta-analysis. Endosc Int Open 2019; 7: E1474-E1482

[169] Taibi A, Durand Fontanier S, Derbal S et al. What is the ideal indwelling time for metal stents after endoscopic ultrasound-guided gastrojejunostomy? Case report of delayed iatrogenic perforation with a review of the literature Dig Endosc 2020; 32: 816-822

[170] Bronswijk M, Fransen L, Vanella G et al. Successful treatment of superior mesenteric artery syndrome by endoscopic ultrasound-guided gastrojejunostomy. Endoscopy 2021; 53: 204-205

[171] Sobani ZA, Rustagi T. Endoscopic ultrasound-guided gastrojejunostomy for the management of superior mesenteric artery syndrome. Am J Gastroenterol 2020; 115: 634-635

[172] Xu MM, Dawod E, Gaidhane M et al. Reverse endoscopic ultrasoundguided gastrojejunostomy for the treatment of superior mesenteric artery syndrome: a new concept. Clin Endosc 2020; 53: 94-96

[173] Kozarek RA, Botoman VA, Patterson DJ. Long-term follow-up in patients who have undergone balloon dilation for gastric outlet obstruction. Gastrointest Endosc 1990; 36: 558-561

[174] Solt J, Rauth J, Papp Z et al. Balloon catheter dilation of postoperative gastric outlet stenosis. Gastrointest Endosc 1984; 30: 359-361

[175] Brewer Gutierrez OI, Irani SS, Ngamruengphong S et al. Endoscopic ultrasound-guided entero-enterostomy for the treatment of afferent loop syndrome: a multicenter experience. Endoscopy 2018; 50: 891-895

[176] Rodrigues-Pinto E, Grimm IS, Baron TH. Efficacy of endoscopically created bypass anastomosis in treatment of afferent limb syndrome: a single-center study. Clin Gastroenterol Hepatol 2016; 14: 633-637

[177] El Bacha H, Leblanc S, Bordacahar B et al. Endoscopic ultrasoundguided enteroenterostomy for afferent limb syndrome. ACG Case Rep J 2020; 7: e00442

[178] Taunk P, Cosgrove N, Loren DE et al. Endoscopic ultrasound-guided gastroenterostomy using a lumen-apposing self-expanding metal stent for decompression of afferent loop obstruction. Endoscopy 2015; 47: (Suppl. 01): E395-E396

[179] De Bie C, Bronswijk M, Vanella G et al. EUS-guided hepaticogastrostomy for patients with afferent loop syndrome: a comparison with EUS-guided gastroenterostomy or percutaneous drainage. Surg Endosc 2021: doi:10.1007/s00464-021-08520-z

[180] Ge PS, Young JY, Dong W et al. EUS-guided gastroenterostomy versus enteral stent placement for palliation of malignant gastric outlet obstruction. Surg Endosc 2019; 33: 3404-3411

[181] Chavan R, Ramchandani M, Nabi Z et al. Luminal and extraluminal bleeding during EUS-guided double-balloon-occluded gastrojejunostomy bypass in benign gastric outlet obstruction with portal hypertension. VideoGIE 2020; 5: 64-67

[182] Kastelijn JB, Moons LMG, Garcia-Alonso F] et al. Patency of endoscopic ultrasound-guided gastroenterostomy in the treatment of malignant gastric outlet obstruction. Endosc Int Open 2020; 8: E1194-E1201

[183] Bukhari M, Kowalski T, Nieto J et al. An international, multicenter, comparative trial of EUS-guided gastrogastrostomy-assisted ERCP versus enteroscopy-assisted ERCP in patients with Roux-en-Y gastric bypass anatomy. Gastrointest Endosc 2018; 88: 486-494

[184] Prakash S, Elmunzer B], Forster EM et al. Endoscopic ultrasounddirected transgastric ERCP (EDGE): a systematic review describing the outcomes, adverse events, and knowledge gaps. Endoscopy 2021: doi:10.1055/a-1376-2394

[185] Attam R, Leslie D, Arain MA et al. EUS-guided sutured gastropexy for transgastric ERCP (ESTER) in patients with Roux-en-Y gastric bypass: a novel, single-session, minimally invasive approach. Endoscopy 2015; 47: 646-649 
[186] Runge TM, Chiang AL, Kowalski TE et al. Endoscopic ultrasounddirected transgastric ERCP (EDGE): a retrospective multicenter study. Endoscopy 2021; 53: 611-618

[187] Tonnesen C], Young J, Glomsaker T et al. Laparoscopy-assisted versus balloon enteroscopy-assisted ERCP after Roux-en-Y gastric bypass. Endoscopy 2020; 52: 654-661

[188] Wang T], Thompson CC, Ryou M. Gastric access temporary for endoscopy (GATE): a proposed algorithm for EUS-directed transgastric ERCP in gastric bypass patients. Surg Endosc 2019; 33: 20242033

[189] Kochhar GS, Mohy-Ud-Din N, Grover A et al. EUS-directed transgastric endoscopic retrograde cholangiopancreatography versus laparoscopic-assisted ERCP versus deep enteroscopy-assisted ERCP for patients with RYGB. Endosc Int Open 2020; 8: E877-E882
[190] Dhindsa BS, Dhaliwal A, Mohan BP et al. EDGE in Roux-en-Y gastric bypass: How does it compare to laparoscopy-assisted and balloon enteroscopy ERCP: a systematic review and meta-analysis. Endosc Int Open 2020; 8: E163-E171

[191] Kedia P, Tarnasky PR, Nieto J et al. EUS-directed transgastric ERCP (EDGE) versus laparoscopy-assisted ERCP (LA-ERCP) for Roux-en-Y gastric bypass (RYGB) anatomy: a multicenter early comparative experience of clinical outcomes. J Clin Gastroenterol 2019; 53: $304-$ 308

[192] Hassan C, Ponchon T, Bisschops R et al. European Society of Gastrointestinal Endoscopy (ESGE) Publications Policy - Update 2020. Endoscopy 2020; 52: 123-126 